\title{
Update on Antibacterial Resistance in Low-Income Countries: Factors Favoring the Emergence of Resistance
}

\author{
Jordi Vila ${ }^{*}, 1$ and Tibor Pal ${ }^{*}, 2$ \\ ${ }^{I}$ Department of Clinical Microbiology, Hospital Clinic, IDIBAPS, School of Medicine, University of Barcelona, \\ Barcelona, Spain \\ ${ }^{2}$ Department of Microbiology and Immunology, FMHS, UAE University, Al Ain, United Arab Emirates
}

\begin{abstract}
Antimicrobial resistance has increased drastically in recent years in the developing countries, and it has rapidly become a leading public health concern. The prevalence of antimicrobial resistance varies greatly between and within countries and between different pathogens. However, overall a trend to the increase of the resistance to those antimicrobial agents more often used in these countries has been observed. Several factors can contribute to the rapid emergence and dissemination of antimicrobial resistance. In this paper, the current antimicrobial resistance in different microorganisms from different countries as well as the factors contributing to the emergence and spread of resistance in developing countries will be reviewed.
\end{abstract}

Keywords: Antimicrobial agents, resistance, developing countries, enteric pathogens, M. tuberculosis, S. pneumoniae, S. aureus.

\section{INTRODUCTION}

Antimicrobial resistance has increased drastically in recent years in both developed and developing countries and it has rapidly become a leading public health concern. The prevalence of antimicrobial resistance varies greatly between and within countries and between different pathogens. Multiresistant microorganisms, which in developed countries would result in the selection of an alternative treatment and hence increased expenses, in poor countries may cause infections that due to practical purposes are untreatable. Several factors can contribute to the rapid emergence and dissemination of antimicrobial resistance. Among these, inadequate access to all antimicrobial agents and health care system, poverty and malnutrition and the abuse of antibiotics should be highligted. According to some estimates, as much as $50 \%$ of antibiotic use is inapropriate because the uses do not benefit the patients. These uses do increase selection pressure for the emergence and spread of antibiotic-resistant bacteria. The emergence of multi-drug-resistant isolates in tuberculosis, acute respiratory infections and diarrhea, often referred to as diseases of poverty, has had its greatest toll in developing countries. The epidemic of HIV/AIDS, with over 30 million cases in developing countries, has greatly enlarged the population of immunocompromised patients. In this paper the current antimicrobial resistance in different microorganisms from different countries as well as the factors contributing to the emergence and spread of resistance in developing countries will be reviewed. However, it is important to mention that the quality of the

*Address correspondence to these authors at the Department of Clinical Microbiology, Hospital Clinic, IDIBAPS, School of Medicine, University of Barcelona, Barcelona, Spain; Tel: + 34-93-227 5522; Fax: + 34-93-227 54 54; E-mail: jvila@ub.edu and Department of Microbiology and Immunology, FMHS, UAE University, Al Ain, United Arab Emirates;

Tel: +97137137480; Fax: +9713 7671966; E-mail: tpal@uaeu.ac.ae microbiological data derived from developing countries is the highly variable. Often, the methods used in the laboratories are poor or not described; no systems for quality control are in place, with small numbers of key pathogens and use of inadequate antimicrobial susceptibility testing panels.

\section{ENTERIC PATHOGENS}

\section{Escherichia coli}

These microorganisms are associated with both extraintestinal and intestinal infections; among the former, the urinary tract infections are the most prevalent. Currently, six different pathotypes of $E$. coli, with different virulence traits, causing intestinal infections are accepted. These have been termed as enterotoxigenic $E$. coli (ETEC), enteroaggregative $E$. coli (EAEC), enteropathogenic $E$. coli (EPEC), diffuse adhering $E$. coli (DAEC), enteroinvasive $E$. coli (EIEC), and enterohemorrhagic $E$. coli or verotoxigenic E. coli (EHEC/VTEC) $[1,2]$. EIEC and EHEC have a lower prevalence as a cause of diarrhea in developing countries compared to the other pathotypes [2]. In addition, recent data suggest that in patients with infection caused by enterohemorrhagic E. coli $\mathrm{O} 157: \mathrm{H} 7$ the treatment increases the risk of the hemolytic uremic syndrome [1].

Uropathogenic E. coli. There is not much data concerning antimicrobial resistance in bacteria causing urinary tract infections (UTI) in developing countries. In some of these countries and mainly in rural areas, many patients cannot afford medical expenses, therefore they undergo urine analysis only in case of repeated or complicated UTI and this can create a bias in the data generated. In a report from Dakar (Senegal) [3], on analyzing 1010 non-duplicate E. coli from 2004 to 2006, the resistance to amoxicillin was $73 \%$, amoxicillin-clavulanic acid $(67.5 \%)$, trimethoprim-sulfamethoxazole $(68 \%)$, whereas the 
resistance to nalidixic acid, norfloxacin and ciprofloxacin was $23.9 \%, 16.4 \%$ and $15.5 \%$, respectively. Most of the strains were susceptible to gentamicin, nitrofurantoin and fosfomycin (respective susceptibility rates, $6.2 \%, 10.1 \%$, and $0.7 \%)$. Only $38(3.7 \%)$ out of $1010 \mathrm{E}$. coli isolates produce extended-spectrum beta-lactamases. Similar levels of resistance (over $73 \%$ for ampicillin and $63 \%$ for cotrimoxazole) have been reported for uropathogenic E. coli from other developing countries (Table 1) [4-8]. In a study performed in Madagascar, $3.1 \%$ of the E. coli harboured extended-spectrum beta-lactamases. However, higher rates of resistance to cefotaxime (46\% among $E$ coli, and $51 \%$ among Klebsiella), suggesting production of extendedspectrum beta-lactamase, have also been reported in developing countries [9]. In addition, these strains frequently show coresistances to other classes of antibacterial agents. The resistance to ciprofloxacin is very variable ranging from $8 \%$ in Central African Republic to $72 \%$ in India. The high level of resistance in this country is likely associated with the consumption of this antimicrobial agents in these countries.

Enterotoxigenic E. coli. ETEC are an important cause of diarrhea among children in the developing world $[1,10]$. Contaminated food and water are the usual sources for ETEC. In some countries such as in Egypt, ETEC may account for $70 \%$ of all first episodes [11] A statistically significant difference between the dry and rainy season was found in a study performed in Tanzania, being more prevalent during the rainy season [12]. During the rainy season there is an enhanced contamination of surface water with fecal material and the surface water can thus become heavily contaminated [13]. Overall, the percentages of resistance of ETEC bearing the stable (ST) or labile (LT) toxins or both are very similar, with figures above $40 \%$ for ampicillin, tetracycline, and trimethoprim-sulfamethoxazole. Chloramphenicol shows activity against ETEC with percentages of resistance ranging from 13 to $57 \%$ (Table 1). Both enterotoxins and genes encoding resistant determinants can be located in a conjugative plasmid [14], suggesting that antibiotic selective pressure could result in a wider distribution of ETEC [15]. There are no significant statistical differences among the different geographical areas analyzed. Similar levels of resistance were observed among these recent reports and previously published studies in the 1980s $[12,16]$. Nalidixic acid or ciprofloxacin show the best activity against these microorganisms. However, a trend to a rise in quinolone resistance has recently been described, possibly following the increase in the use of quinolones for other diseases resistant to quinolones, mainly in India [17]. Nalidixic acid was introduced a few years ago as the firstline therapy for shigellosis in some areas of India and therefore ETEC strains resistant to nalidixic acid are now emerging.

Enteroaggregative E. coli. EPEC, DAEC and EAEC can be distinguished according to their patterns of adherence to HEp-2 cells. EPEC forms a microcolony-forming pattern, DAEC a diffuse adherence pattern and EAEC a aggregative or "stacked-brick" pattern. Long time ago, Nataro and colleagues showed significant association of EAEC with diarrhea in chilean children [18]. EAEC has been related to persistent diarrhea in children in developing countries likely associated with biofilm production [19]. The prevalence of EAEC as a cause of diarrhea in children has been found higher during the dry season than in the rainy season [20]. Multidrug resistant EAEC have been reported in Kenya, Nigeria, Tanzania, Peru, and Thailand (see Table 1) [12,16,21-23]. In almost all studies the percentages of resistance to ampicillin, chloramphenicol, tetracycline and co-trimoxazole were above $50 \%$. In an unpublished study, we have recently found 5 EAEC clinical isolates causing diarrhea in patients returning from India, which were resistant to third generation cephalosporins, and this resistance was associated with the presence of the $b l a_{\text {CTX-M-15 }}$ gene in isolates from the Middle East and from India [24, unpublished data].

One alternative for the treatment of enteritis caused by EAEC is the use of quinolones. However, they are not recommended for children. Although ciprofloxacin is recommended as the drug of choice to treat traveler's diarrhea, high percentage of resistance to this antimicrobial agents has been reported in ETEC and EAEC isolated from travellers to North Africa and India, reflecting the current situation in these countries [17].

Enteropathogenic $\boldsymbol{E}$. coli. EPEC causes diarrhea in infants in developed and developing countries as well as in travelers [2, 12, 25]. The percentages of antimicrobial resistance are similar to those described for the other diarrheagenic $E$. coli, with a level of resistance above $23 \%$ to ampicillin, tetracycline, and trimethoprim-sulfamethoxazole, moderate resistance to chloramphenicol, and almost no strains resistant to quinolones (see Table 1). Although antibiotics are often used to treat enteritis caused by EPEC, there is no definitive evidence that treatment shortens the clinical course.

\section{Shigella spp.}

Infections caused by Shigella species are an important cause of diarrheal diseases, in both developing and developed countries. Worldwide, it is estimated that shigellosis causes around 600,000 death per year, two-thirds of the deceased being children under 10 years of age. Shigella dysenteriae and Shigella flexneri are the predominant species in developing countries, whereas Shigella sonnei is predominant in industrialized countries [26]. Shigella spp. are transmitted from person to person, although food and water can also be contaminated. Infection is possible due to the low inoculum required (as few as 10 microorganisms). The percentages of resistance to several antimicrobial agents in the three main species of Shigella isolated from different geographical areas (mainly developing countries) are shown in Table 1 [16, 27-33]. Overall, $S$. flexneri and $S$. dysenteriae are more resistant than $S$. sonnei, at least when ampicillin and chloramphenicol were tested. The prevalence of resistance to ampicillin for $S$. sonnei ranges from a low of $0 \%$ in Calcutta (India) to a high of $62 \%$ in Vietnam [28, 33]. Similarly, the rate of chloramphenicol resistance is very wide, being from $0 \%$ in Western Kenya or Tanzania to $44.3 \%$ in Korea [30, 32, 34]. In most of the geographical areas analyzed, the resistance to trimethoprim-sulfamethoxazole in three species of Shigella ranged from 55 to $100 \%$, and was higher than that previously reported, showing a trend to an increase in resistance to these antimicrobial agents in Shigella spp clinical isolates. However, most of the scientific literature on antimicrobial 
Table 1. Antimicrobial Resistance in Enteric Pathogens Isolated in Developing Countries

\begin{tabular}{|c|c|c|c|c|c|c|c|c|c|}
\hline Bacteria/Country & AMP & CHL & TET & SXT & CTX & CFR & NAL & CIP & Ref. \\
\hline \multicolumn{10}{|l|}{ UPEC } \\
\hline Central African Republic & 80 & --- & --- & 80 & 0 & 0 & 9 & 8 & {$[4]$} \\
\hline Índia & 85 & --- & --- & 74 & --- & --- & --- & 72 & {$[5]$} \\
\hline Madagascar & 74 & --- & --- & 69.5 & 3.1 & 3.1 & 25 & 16 & {$[6]$} \\
\hline Nicaragua & 74 & --- & --- & 63 & --- & 0 & --- & 30 & [7] \\
\hline Senegal & 73 & --- & --- & 68 & 3.5 & --- & 24 & 16 & [3] \\
\hline Sudan & 75 & -- & --- & 67 & -- & 19 & 6 & -- & [8] \\
\hline \multicolumn{10}{|l|}{ ETEC } \\
\hline Tanzania & 84 & 25 & 68 & 79.5 & --- & --- & 2.3 & 0 & [12] \\
\hline Thailand & 54 & 13 & 43 & 51 & --- & --- & 3 & 2 & [16] \\
\hline Vietnam & 71 & 57 & --- & 71 & --- & --- & 14.3 & 7.1 & {$[16]$} \\
\hline \multicolumn{10}{|l|}{ EAEC } \\
\hline Kenya & & & & & & & & & {$[21]$} \\
\hline Nigeria & 81 & 46.5 & 95.4 & 74 & -- & --- & 0 & 0 & {$[22]$} \\
\hline Tanzania & 83 & 57 & 88 & 91 & --- & --- & 1.5 & 0 & {$[12]$} \\
\hline Vietnam & 90 & 87 & --- & 92 & --- & --- & 19 & 0 & {$[16]$} \\
\hline \multicolumn{10}{|l|}{ EPEC } \\
\hline Tanzania & 90 & 33 & 81 & 90 & -- & -- & 0 & 0 & {$[12]$} \\
\hline Uruguay & 100 & 27 & 23 & 42 & --- & --- & --- & 0 & {$[25]$} \\
\hline Vietnam & 82 & 64 & --- & 84 & --- & --- & 24 & 10 & {$[16]$} \\
\hline \multicolumn{10}{|l|}{ Shigella flexneri } \\
\hline Brazil & 100 & --- & --- & 55 & -- & --- & 0 & --- & {$[27]$} \\
\hline India & 87 & 58 & 100 & 100 & --- & --- & 21 & 0 & [28] \\
\hline Indonesia & 90 & 83 & 94 & 80 & -- & --- & -- & 0 & [29] \\
\hline Kenya & 94 & 90 & 99 & 88 & -- & --- & 2 & 0 & [30] \\
\hline Rwanda & 83 & 80 & --- & 75 & --- & --- & 0.5 & 0 & [31] \\
\hline Tanzania & 92 & 92 & 99 & 92 & --- & --- & 0 & 0 & {$[32]$} \\
\hline Thailand & 82 & 61 & 96 & 86 & --- & -- & 0 & 0 & {$[16]$} \\
\hline Vietnam & 85 & 85 & --- & 85 & --- & --- & 0 & 0 & [33] \\
\hline \multicolumn{10}{|l|}{ Shigella sonnei } \\
\hline India & 0 & 25 & 100 & 100 & --- & --- & 25 & 0 & {$[28]$} \\
\hline Indonesia & 27 & 17 & 83 & 76 & --- & --- & --- & 0 & [29] \\
\hline Kenya & 5 & 0 & 98 & 100 & --- & --- & 0 & 0 & {$[30]$} \\
\hline Rwanda & 13 & 7 & --- & 38 & --- & -- & 0 & 0 & {$[31]$} \\
\hline Tanzania & 25 & 0 & 100 & 100 & --- & --- & 0 & 0 & {$[32]$} \\
\hline Thailand & 4 & 3 & 92 & 97 & --- & --- & 0 & 0 & {$[16]$} \\
\hline Vietnam & 70 & 40 & -- & 90 & -- & --- & 5 & 0 & [33] \\
\hline \multicolumn{10}{|l|}{ Shigella dysenteriae } \\
\hline India & 100 & 80 & 100 & 100 & --- & --- & 60 & 0 & {$[28]$} \\
\hline Indonesia & 100 & 100 & 100 & 100 & --- & --- & --- & 0 & [29] \\
\hline Kenya & 98 & 100 & 100 & 95 & --- & --- & 0 & 0 & {$[30$} \\
\hline Rwanda & 100 & 100 & --- & 68 & --- & --- & 20 & 0 & [31] \\
\hline Tanzania & 100 & 100 & 100 & 100 & --- & --- & 0 & 0 & [32] \\
\hline Thailand & 0 & 0 & 33 & 0 & --- & --- & 0 & 0 & [16] \\
\hline Vietnam & 50 & 17 & 50 & 50 & --- & --- & 0 & 0 & [33] \\
\hline
\end{tabular}




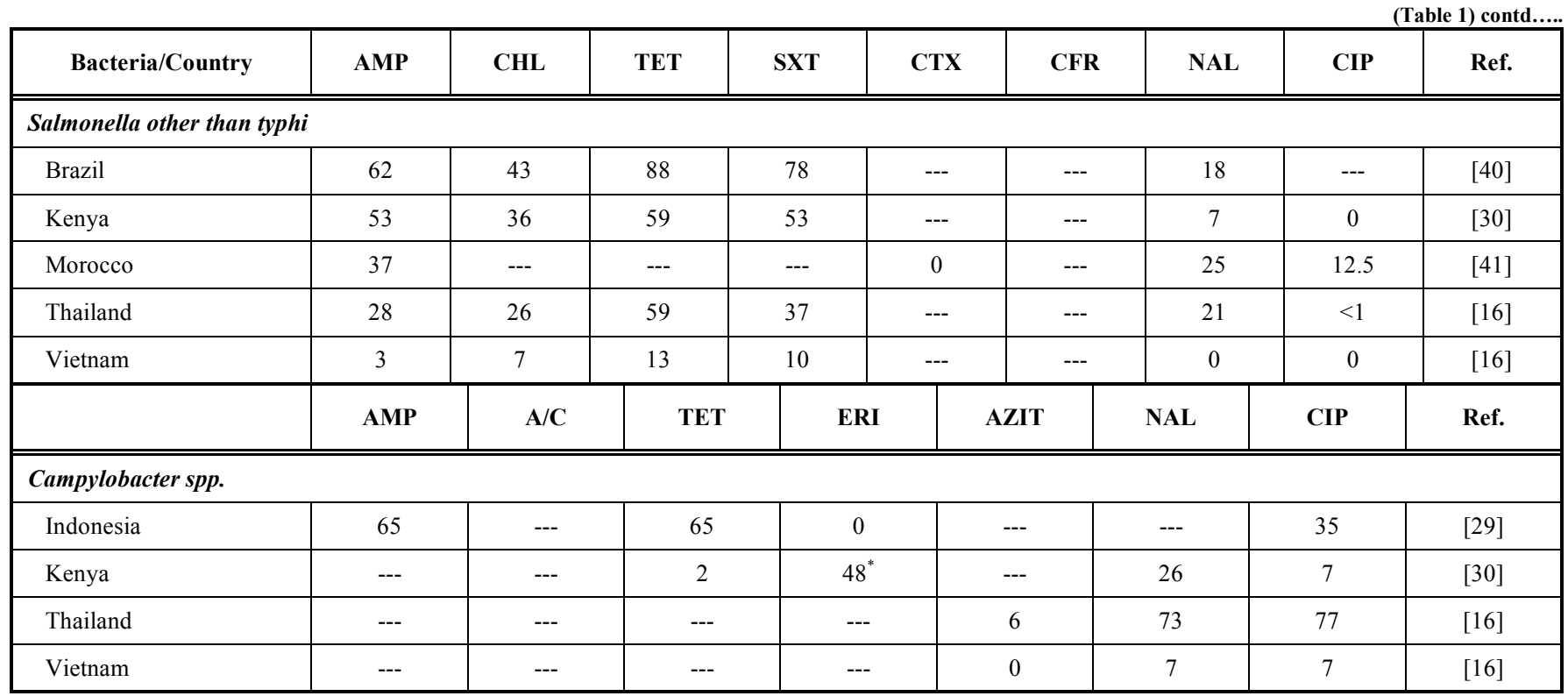

$\mathrm{UPEC}=$ Uropathogenic $E$. coli; $\mathrm{ETEC}=$ enterotoxigenic $E$. coli; $\mathrm{EAEC}=$ enteroaggregative $E$. coli; $\mathrm{EPEC}=$ enteropathogenic $E$. coli. $\mathrm{AMP}=$ ampicillin; $\mathrm{CHL}=$ chloramphenicol $\mathrm{TET}=$ tetracycline; SXT $=$ co-trimoxazole; $\mathrm{CTX}=$ cefotaxime; $\mathrm{CFR}=$ cefuroxime; $\mathrm{NAL}=$ nalidixic acid; $\mathrm{CIP}=$ ciprofloxacin; $\mathrm{A} / \mathrm{C}=$ amoxicillin $/$ clavulanic acid; ERI $=$ erythromycin; AZIT = azithromycin.

resistance in Shigella spp do not analyze the epidemiological relationship among the isolates. Nonetheless, a predominant multiresistant clone is probably responsible for this high frequency of resistance [32]. Although no resistance to fluoroquinolones, such as ciprofloxacin, has been detected, the percentage of resistance to nalidixic acid ranges from $0 \%$ in several geographical areas to $100 \%$ in strains of S. sonnei in Korea [34]. However, the latter figures may be attributed to the spread of a resistant clone. Moreover, a trend to quinolone resistance has been observed in $S$. dysenteriae strains isolated in Burundi [35] Although the level of resistance to nalidixic acid can be as high as $25 \%$ in some countries such in India [36], the level of resistance to ciprofloxacin remains very low. An association between fluoroquinolone resistance acquisition and decrease of colonization/invasion of the intestinal epithelia in Salmonella, which may explain the above mentioned situation, has recently been reported [37].

\section{Salmonella spp.}

Salmonella gastroenteritis is a well-known disease that occurs throughout the world. In industrialized nations, this large group of organisms is the most common cause of outbreaks of food associated diarrhea [38]. Salmonella is transmitted to humans by ingestion of the microorganism in contaminated food, although fecal-oral transmission from person to person has also been described [38].

Between 1980 and 1984, the susceptibility data for Salmonella strains from different tropical countries were compiled to predict significant patterns or trends [39]. The percentages of resistance to ampicillin, tetracycline, chloramphenicol, and trimethoprim-sulfamethoxazole were quite variable, with the lowest rates found in Sri Lanka, the percentages ranging from $3 \%$ (resistance to chloramphenicol) to $10 \%$ (resistance to trimethoprim) [39]. In recent studies (Table 1), the resistance to the abovementioned antibiotics among Salmonella spp. has also varied among the different developing countries, with Vietnam showing the lowest rate [16]. The resistance to fluoroquinolones is very wide going from $0 \%$ in Vietnam to $21 \%$ in Thailand two neighbouring countries (see Table 1). However, in a recent study a reduced susceptibility to ciprofloxacin (MIC, 0.125 to $1 \mathrm{mg} / \mathrm{L}$ ) in non-typhoid Salmonella isolates was commonly observed in Taiwan (48\%) and Thailand (46\%) [42]. Meanwhile reduced susceptibility to ceftriaxone (MIC, 2 to $8 \mathrm{mg} / \mathrm{L}$ ) remained uncommon in Asia, except in Taiwan (38\%) or in $S$. Typhimurium (25\%) from all countries suggesting the potential implications of ESBLs [42]. Antibiotic therapy is not recommended for most uncomplicated cases since infection is most often self-limited [38]. The administration of antimicrobial agents may prolong shedding, and antimicrobial resistance to all agents that have been used for treatment has been seen. Antibiotics should be considered for infants of less than 2 months of age, the elderly, and patients with sickle cell disease, advanced HIV infection, high fever, evidence of focal infection outside the gastrointestinal tract, or bacteremia. When therapy is indicated, the choice of agents includes a third generation cephalosporin or one of the fluoroquinolones.

\section{Campylobacter spp.}

Campylobacter species associated with gastrointestinal infectious diseases include Campylobacter jejuni, Campylobacter coli, Campylobacter lari, and Campylobacter upsaliensis. The most common species implicated are $C$. jejuni and $C$. coli. $C$. jejuni is a common cause of diarrhea throughout the world. Campylobacter spp. are found in foods primarily of animal origins, particularly poultry. The resistance frequency to ampicillin and tetracycline in $C$. jejuni is usually very high (Table 1) [16, 29, 30]. Macrolides, either erythromycin or azithromycin, are the most active antibiotics against $C$. jejuni. Among 15 of 16 Peruvian children presenting with $C$. jejuni related dysentery, stool became normal within 5 days when treated with erythromycin, in contrast to only 6 of 12 children who received placebo [43]. Studies in adults with enteritis caused 
by Campylobacter have indicated that treatment with either ciprofloxacin or azithromycin shortened the duration of symptoms [44]. In general, resistance to fluoroquinolones in C. jejuni goes from $7 \%$ to $77 \%$ in some areas such as Thailand, Mali, and Burkina-Faso [16, unpublished data] (Table 1). These high figures are similar to those found in some industrialized countries. At the end of the 1980s, several studies showed minimal resistance to fluoroquinolones among Campylobacter species [45]. Recently, there has been a trend toward an increased frequency of quinolone resistance concomitant with the increased use of fluoroquinolones in humans and animals [46].

Few years ago, if antimicrobial therapy was indicated for Campylobacter infections, azythromycin and fluoroquinolones were considered the drugs of choice. Since the symptoms of Campylobacter enteritis are clinically indistinguishable from those of enteritis caused by other bacteria, most physicians prescribed fluoroquinolones empirically, which covered all bacterial enteropathogens. However, due to the rapid increase in the isolation of fluoroquinolone-resistant Campylobacter strains, erythromycin should currently be considered as the drug of choice to treat Campylobacter infections. The severity of the illness may be lessened by the early administration of antibiotics during the course of the disease. Antimicrobial treatment may be appropriate for patients with high fever, bloody stools, and more than 8 stools within a 24-hour period. Immunocompromised hosts and patients with bacteremia should also be treated [47].

\section{Other Enteric Bacteria}

Although Vibrio cholerae infections are important in some endemic areas, they have often been described as cause of outbreaks in Asia, Africa and South America. Historically, epidemics have been due to serogroup O1 strains. In the early 1990s, a new serotype strain, Bengal O139, began a new wave of cholera epidemics. The primary treatment of cholera is oral rehydration to replace the massive fluid loss that occurs. Antibiotics are also recommended to shorten the duration of illness and bacterial shedding. Currently, the treatment of choice is tetracycline, although trimethoprim-sulfamethoxazole or a fluoroquinolone may also be used. However, some isolates causing outbreaks as well as sporadic strains have been shown to be tetracycline or trimethoprim-sulfamethoxazole resistant [48]. Ciprofloxacin possess excellent activity against $V$. cholerae 01 and 0139 serogroups, and it is an effective treatment of cholera in adults and children. However, in Calcutta, India, the incidence of nalidixic acid resistance among $V$. cholerae $\mathrm{O} 1$ strains was low $(<10 \%)$ before 1993 and increased to $100 \%$ in 1999 [49, 50].

Other potential bacterial pathogens, including Aeromonas spp, Plesiomonas shigelloides, and Yersinia enterocolitica are known to cause diarrhea in developing countries at a low prevalence. Among the Aeromonas genospecies, those considered for clinical relevance are Aeromonas hydrophila, Aeromonas caviae, and Aeromonas veronii biotype sobria. Nearly all the studies in developing countries on the prevalence of Aeromonas spp. as a cause of diarrhea have been reported from children. A. veronii biotype sobria and
Aeromonas caviae are most frequently related to diarrhea in children in developing countries [51]. Several outbreaks have been reported from developing countries. One reported from India in children admitted to the hematology-oncology unit, who developed acute diarrhea by $A$. veroni biovar sobria [52]. Aeromonas spp show high levels of resistance to nalidixic acid and ciprofloxacin in India [53]. P. shigelloides have been suggested, but not firmly established, as a cause of gastrointestinal infection. These microorganisms have been found to be part of the normal gastrointestinal flora in up to $3 \%$ of individuals. The microorganism is variably susceptible in vitro to chloramphenicol, tetracycline, trimethoprim-sulfamethoxazole, aminoglycosides, fluoroquinolones, imipenem, and third generation cephalosporins, and is naturally resistant to several antimicrobial agents such as penicillins, and some cephalosporins such as cefoperazone, ceftazidime, and cefepime [54]. Y. enterocolitica are isolated as the cause of diarrhea in developing countries, but the infection appears to occur predominantly in cooler climates. Therefore, there are not many reports on the antimicrobial susceptibility of this microorganism as a cause of diarrhea in developing countries. All the isolates causing traveller's diarrhea, which can mimic the microbiota of developing countries were resistant to ampicillin, but susceptible to tetracycline, nalidixic acid, and ciprofloxacin. Resistance to chloramphenicol and trimethoprim-sulfamethoxazole was less frequent (8\%) [Vila et al. unpublished data].

\section{NON-FERMENTATIVE GRAM-NEGATIVE BACTERIA}

\section{Pseudomonas aeruginosa and Acinetobacter baumannii}

$P$. aeruginosa are mainly found in moist environments (respiratory equipment, sinks, tap water,..), whereas $A$. baumannii can survive in dry environments more than 20 days, a feature likely associated with the production of biofilm (Vila et al., Unpublished data). The most important part of the infections caused by these microorganisms takes place in intensive care units. Late-onset ventilator-associated pneumonia is likely the most frequent infectious diseases caused by these microorganisms in both developed and developing countries. However, considering A. baumannii many times it is not easy to differentiate between colonization and infection. In a recent paper [55], the antimicrobial resistance of different microorganisms causing hospital-acquired pneumonia in 10 Asian countries was analyzed. The resistance of $P$. aeruginosa to ceftazidime ranged from 3 to $48 \%$, from 3 to $35 \%$ for imipenem, from 4 to $44 \%$ for ciprofloxacin and from 2 to $30 \%$ for piperacillintazobactam. Meanwhile, the resistance of A. baumannii to imipenem and ciprofloxacin ranged from 2 to $77 \%$ and 23 to $92 \%$, respectively. Multidrug resistant $P$. aeruginosa has also been shown in Cameroon [56], where $41.2 \%$ of the clinical isolates showed resistance to at least four antimicrobial agents. The SENTRY Program findings in the Latin American region were in agreement with previous local studies, demonstrating that increasing resistance to commonly used anti-pseudomonal agents is a major therapeutic issue. Furthermore, the report clearly indicates that antimicrobial resistance among $P$. aeruginosa isolates in Latin American countries has increased significantly over a relatively short time period. This upward trend may reflect differences in antimicrobial prescription practices and/or a 
more frequent dissemination of MDR clones in the countries participating in the SENTRY Program [57].

A. baumannii can be considered as the paradigm of multiresistant bacteria. It is highly prevalent in different Asian as well as South America countries, however, little attention has been given to the prevalence of this microorganism in Africa. Special mention is needed for some panresistant A. baumannii strains. For instance, $18.3 \%$ of Acinetobacter isolated in Korea were resistant to all antimicrobial agents tested [58], whereas $6 \%$ of the analyzed clinical isolates in Taiwan showed this panresistant phenotype. In India, Acinetobacter has been found to be an important nosocomial pathogen in intensive care units demonstrating extended drug resistance, thus, resistant to all antimicrobial agents but colistin [59]. According to the SENTRY reports, resistance rates for $A$. baumannii are higher in Latin American countries than in the USA or Europe. The prevalence of carbapenem resistance in $A$. Baumannii, across Latin America in the SENTRY database in 2001, was estimated at $25 \%$ [57]. The emergence of panresistant $A$. baumannii clinical isolates makes new therapeutic alternatives necessary [60].

Global dissemination of eight carbapenem-resistant $A$. baumannii lineages has recently been shown, illustrating the success this organism has had in epidemic spread. Among these different lineages, European clone II was disseminated to the USA, Europe, Israel, Asia, Australia and South Africa [61].

\section{GRAM-POSITIVE COCCI}

\section{Streptococcus pneumoniae}

According to a recent estimate, in the year 2000 approximately 14.5 million episodes of serious Streptococcus pneumoniae infections occurred causing about 826,000 deaths in children below 5 years of age. Consequently, S. pneumoniae alone accounted for $11 \%$ of deaths in this age group. Not surprisingly figures are heavily skewed towards the developing world: $61 \%$ of the 735,000 victims (not co-infected with HIV) came from 10 African and Asian countries [62]. However, serious, life threatening infections are not the only problems associated with $S$. pneumoniae exhibiting increasing drug resistance: acute otitis media is the commonest disease following the colonization of the upper respiratory tract [63], and this pathogen is the most frequent isolate from the middle ear worldwide [64].

Most concerns related to the decreased antibiotic susceptibility in S. pneumoniae have been centered on two groups of drugs, i.e. beta-lactams and macrolides. This holds true even in the light of accumulating proof showing that most non-meningitis infections due to beta-lactam intermediately resistant strains respond well to increased doses of the drugs. This resulted in the recent re-evaluation of the interpretation criteria of beta-lactam breakpoint values for $S$. pneumoniae distinguishing between central nervous system isolates (with MIC values for parenteral penicillin, susceptible: $\leq 0.06 \mathrm{~g} / \mathrm{L}$, resistant $\geq 0.12 \mathrm{~g} / \mathrm{L}$ ) from those recovered from non-meningitis cases (susceptible: $\leq 2 \mathrm{~g} / \mathrm{L}$, intermediate: 4 , resistant $\geq 8 \mathrm{~g} / \mathrm{L}$ with similar changes for cephalosporins, as well) [65]. Caution should always be exercised when comparing results obtained by testing respiratory and invasive, particularly meningitis isolates. However, these changes in interpretation criteria further emphasize the need for careful interpretation of data. Earlier studies may have applied more stringent criteria to respiratory isolates as well, using the formerly accepted, general $\geq 2 \mathrm{~g} / \mathrm{L}$ breakpoint value for resistance. This may have resulted in over-estimating real incidences of resistance among non-meningitis isolates while underestimating them among strains isolated from the central nervous system. The effect of different interpretation criteria was clearly shown recently by Hsieh $Y-C$ et al. [66] reporting on sterile-site isolates recovered from over 500 invasive disease episodes in Taiwan during 2007. While $67.8 \%$ of the isolates were non-suceptible to penicillin using the meningitis criteria, only $7.7 \%$ fell into this catergory with the non-meningitis breakpoints. Corresponding figures for ceftriaxone were $50.5 \%$ and $14 \%$, respectively.

Large scale antibiotic surveillance projects such as the PROTEKT or GLOBAL studies $[67,68]$ revealed a considerably uneven distribution of penicillin resistance among $S$. pneumoniae isolates. According to the former study, more than a third of all respiratory tract isolates had reduced susceptibility to penicillin. However, respective figures from South Africa, the Far East and from the Middle East, i.e. regions with several developing countries, were much higher, being $74 \%, 63 \%$ and $54 \%$, respectively [67]. Similarly, skewed distribution of penicillin nonsusceptibility towards developing regions was found by the GLOBAL study [68].

It is noteworthy that incidence figures exhibit not only a variation between areas of the world, but also remarkable variations exist within the regions. This was shown among respiratory tract $[69,70]$ and mixed [71] isolates in South America, among mixed [71] and invasive [72, 73] isolates in Africa, the Mediterranean region [74] and the Arabian Peninsula [75-77]. Notably, trends may differ in distinct parts of the same region: between 2003 and 2005 a more than $50 \%$ decrease in the proportion of non-susceptible invasive strains was observed in Egypt, while an increase from $12.8 \%$ to $24.3 \%$ was experienced during the same time in Turkey. Due to the relatively low number of isolates involved in these studies, however, further, extensive surveillances should exclude timely, quickly reversible fluctuations [74].

Mostly, the Far Eastern region is hit by the problem of beta-lactam resistant pneumococci, in general, and it is the same region where the most extensive regional variations have been noticed. In an ANSORP (Asian Network for Surveillance of Resistant Pathogens) study collecting strains from 14 centers in 11 countries in 2000 and 2001, 29.4\% of the isolates were resistant to penicillin and a further $23 \%$ exhibited intermediate susceptibility [78]. However, while in Vietnam $71.4 \%$ of all isolates were resistant (with Korea being the second with $54.8 \%$ resistance), no resistant isolates were found in India or in the Philippines. Furthermore, no direct correlation between the rates of intermediate resistance and that of full resistance was observed. In Sri Lanka, the intermediately resistant strains represented $71.4 \%$ of all isolates and $14.3 \%$ were resistant, while in Vietnam, extremly high figures of resistance (i.e. 71.4\%) were 
supplemented with a further $20.6 \%$ of intermediately resistant isolates only [78].

Recent studies noted further significant increases in penicillin resistance in some areas of the region, notably in Taiwan [66] and in China [79] and most of the regional differences have recently been confirmed [80].

Extended spectrum cephalosporins, particularly cefotaxime and ceftriaxone, are often the drugs of choice to treat invasive $S$. pneumoniae infections, meningitis in particular. Overall, in Asia $0.9 \%$ of the strains were found to be ceftriaxone resistant, although all the isolates came from four countries, i.e. Korea and Vietnam, 3.2-3.2\% each, Malaysia (2.3\%), and China (1.8\%) [78]. A few years later no further increase was noted in the regional rate of ceftriaxone resistance $(0.6 \%)$ (according to "non-meningitis" criteria), although only $83.1 \%$ of the isolates exhibited full susceptibility while $16.3 \%$ were intermediately resistant [68]. Recently, unpublished observations from the CDC of Taiwan were cited providing figures of about $65-70 \%$ resistance to penicillin (compared to the $38.6 \%$ seen previously $-[78]$ ) and a $38 \%$ resistance to ceftriaxone, although no specifics on breakpoints used or on the source of isolates were provided [80].

The remarkable country-to-country variation observed for beta-lactam resistance was also present for macrolides. While isolates from Vietnam, South Korea and Taiwan had over $80 \%$ erythromycin resistance rates, the Philippines, Sri Lanka, Saudi Arabia and in particular in India, it remains below $20 \%$, actually being below $2 \%$ in the latter country [76]. According to the PROTEKT study some countries of South-East Asia had an outstandingly high erythromycin resistance rate, around $80 \%$, with South Africa (about 54\%) and Southern-Europe $(\approx 37 \%)$ following [78].

Although in general, strains resistant to either macrolides or to penicillin are more likely to be resistant to the other drugs, or to other classes, co-trimoxsazole, in particular [74, $78,79,81]$ the link is not direct. When comparing isolates from 9 study centers in 8 cities of China the rate of erythromycin resistance was found to be uniformly high, the lowest rate among the centers being $86.1 \%$. While the rates of cefaclor resistance were also comparatively even (above $65 \%$ in all but one center), penicillin resistance varied between 31 and $89.6 \%$, resistance to amoxicillin/clavulanic acid between 0 and $52.2 \%$ and ceftriaxone resistance between 0 and $62.7 \%$ [78]. Nevertheless, it is clear that multidrug resistance (MDR) is an increasing problem, in particular, in developing countries usually most burdened by non-susceptibility to individual drugs $[74,78,79,81]$. Once studied, MDR strains in developing countries are often found to represent global clones, such as Taiwan ${ }^{19 \mathrm{~F}}$, Spain $^{9 \mathrm{~V}}$ and England $^{14}$ in South Africa [82] or Taiwan ${ }^{19 \mathrm{~F}}$ and Spain $^{23 \mathrm{~F}}$ in Asia [78].

Increased use of the conjugated pneumococcal vaccine may have a beneficial effect on the rate of antibiotic resistant strains in the developing countries as it had in some industrialised parts of the world [83-88]. This anticipation is based on the fact that several serotypes of the heptavalent PCV7 vaccine (containing serotypes 4, 6B, 9V, 14, 18C, 19F and $23 \mathrm{~F}$ ) often exhibit a high level of resistance $[89,90]$. Two problems, however, may interfere with this effect of the vaccine. First, the composition of PCV7 is based on prevalence data collected in developed countries and its current composition may not cover serotypes in other regions of the world to the same extent. Furthermore, non-PCV7 "replacement" serotypes with frequent high level of resistance, e.g. 19A, could occupy the niche created by the suppression of previously dominating vaccine-serotypes [91]. In some developing regions this non-PCV7 serotype is already well represented [79, 80, 92, 93]. Introduction of broad-coverage of vaccines (i.e. PCV10 or 13) is likely to provide solutions to these problems - provided financial constraints permit their wide-spread use.

\section{Enterococcus}

Relatively little is known about the glycopeptide resistance of Enterococcus isolates from the developing countries. A recent study identified vancomycin resistant enterococci (VRE) as the only drug resistant pathogen among isolates from ICUs from 18 developing countries which did not exceed the incidence seen in the respective data from surveys in the US [94]. However, from the sparse data available it seems that the problem is clearly emerging particularly in the developing countries of Asia [95-98], Latin America [99, 100] and Africa [101]. A SENTRY study found $10,3 \%$ of E. faecium and $0.4 \%$ of $E$. faecalis resistant to vancomycin in the Asia-Pacific region [102]. The frequency of VRE among enterococci exhibits considerable variation between countries, but usually remains below to what has been found in the US. Nevertheless, alarmingly high figures from some countries have been reported, such as recently in Teheran with overall $12 \%$ vancomycin resistance among all enterococci, $6 \%$ among E. faecalis and $22 \%$ among E. faecium [103].

Local outbreaks of VRE could be linked to inappropriate use of glycopeptides, as recently reported from Thailand [104], and could be controlled by strict measures, even with limited resources, as in an oncology ward from South Africa, facing a multi-clonal outbreak [105]. Lineages, such as Clonal Complex 17 (CC17) causing the majority of hospital outbreaks has spread globally [106] and is now being isolated from epidemics of developing countries as well [107]. Locally, (and also globally) increased or inappropriate use of glycopeptides can contribute to local emergence or spread of VRE [104,108]. Little is known about the contribution of environmental and animal strains to human infections in these countries. Some of the few studies having addressed this issue found a very high rate of VRE among animal (equid) isolates [109], but their impact on human morbidity is still to be investigated.

\section{Staphylococcus aureus}

Morbidity and mortality rates in high-income countries due to antibiotic resistant Staphylococcus aureus, methicillin resistant strains (MRSA) in particular, have attracted considerable media and public attention. This has accompanied, and to some extent even triggered, professional efforts to understand the reasons for these epidemics and to control them [110]. Irrespective of the success of these efforts, the existence of the problem has been well appreciated and documented in industrialized parts of the world. In the developing countries, however, diseases such as HIV, tuberculosis, malaria, and various enteric and 
pneumococcal infections have been considered to be more important causes of morbidity and mortality than infections due to $S$. aureus $[111,112]$ (and to most antibiotic resistant organisms in general). This, in the past, has considerably limited the attention paid to the emergence and spread of resistance of this pathogen in low income areas $[111,112]$.

While the rate of MRSA in some of the developing countries might still be lower than the burden in countries with higher quality health care infrastructure [113], this is rather an exception than a rule for most developing areas. Strikingly higher figures for the rate of MRSA among $S$. aureus ICU isolates $(80,8 \%)$ were observed in the developing countries than in the reports from the US, which already perceived as being heavily burdened by the problem itself ( 52.9\%) [111].

Furthermore, mortality-related figures due to $S$. aureus/MRSA infections are clearly higher in developing countries. In a recent study analyzing data of 98 patients with $S$. aureus bacteremia in a large regional hospital in Northeast Thailand found that the all-cause, and particularly attributable mortality rate was almost twice as high $(52 \%$ and $44 \%$ ) as cited by some studies from the US. While strains acquired in the community were uniformly sensitive to methicillin, $28 \%$ of the hospital acquired or health carerelated infections ( $54 \%$ of all cases in the study) were caused by MRSA [111]. It is interesting to note that contrary to what has been observed in high income countries, in territories with limited resources invasive cases due to $S$. aureus are more common in the neonatal age [114, 115].

Figures, however, could be extremely variable within a large region, as was shown among isolates from 8 African Hospitals and Malta varying from a $4.8 \%$ rate of MRSA among $S$. aureus in Algeria to nearly $30 \%$ in Nigeria [116]. Nevertheless, in regions where data from different timepoints are available for comparison, an increase in MRSA incidence has been uniformly noted [117-120].

Data from 9 Asian countries suggest that the overwhelming majority of hospital-acquired MRSA infections can be attributed to a single clone, sequence type ST239 [121,122], i.e. a genotype with an extremely broad worldwide distribution [123]. The same clone, among others, was recently found in several hospitals in South Africa and India [124, 125] indicating, as expected, that hospitals in the developing regions are not sealed off from the global trade of clones of pathogens.

Community-acquired MRSA (CA-MRSA), usually characterized by sccmecA types IV or $\mathrm{V}$ and often positive for the genes encoding for Panton-Valentine leukocidine (PVL), are having an increasingly recognized impact on the incidence of MRSA in the community, and lately also in the hospitals in several high income countries. However, very little is known about the epidemiology of CA-MRSA in the developing countries. Since invasive infections, particularly blood stream infections, are the typical clinical presentations causing the most concern of $S$. aureus infections in these regions, this might have diverted attention from infections more consistent with CA-MRSA etiology (e.g. soft tissue infections, fulminant lung infections). Few studies in low income countries accurately distinguish between community and hospital-acquired/health care-related $S$. aureus infections. However once done, data show that the rate of MRSA in the former group is still low in developing countries, particularly among blood stream isolates [111, 112, 126-129]. Some other studies however, do present figures to the opposite [130], particularly when samples more consistent with the anticipated CA-MRSA etiology are investigated. In a recent study from India it was shown that of the 250 pyoderma cases from the community $80.8 \%$ was due to $S$. aureus, of which $10.9 \%$ was MRSA; $54.4 \%$ of the patients carried $S$. aureus in their nares, $11.8 \%$ being resistant to methicillin [131]. Among agents of community acquired thoracic empyema of children in an Indian study $S$. aureus was the most frequently identified pathogen and from 3 children MRSA was isolated [132]. Unfortunately, none of these studies has been complemented with molecular typing data to confirm typical CA-MRSA genotypes and some use only phenotypic surrogate markers, as clindamycin susceptibility, to define "community-acquired-like" isolates [133]. Furthermore, very few of the community-based studies explore previous health care exposure in case of nonnosocomial isolates. Previous connection to health care does have an impact on antibiotic resistance of subsequent isolates as repeatedly shown is industrialized countries, and in a few cases, when studied, in low income settings as well [111, $112,127]$.

Increasing multidrug resistance among MRSA strains is a global problem [134] and was also found commonly in different developing countries, e.g. in Africa [116, 124, 130], in Jamaica [129] and India [120]. It is of particular concern that the emergence of mupirocin resistance (i.e. a drug commonly used to eradicate MRSA from the nares) has been reported already from several developing regions, e.g. Trinidad [135], Africa [124] and the Middle East [136]. The emergence of vancomycin heterointermediately, and intermediately resistant $S$. aureus has been reported from several Asian countries [137-139]. Recently, two vancomycin and teicoplanin resistant strains in India were isolated following vancomycin therapy [140].

\section{OTHER CLINICALLY RELEVANT BACTERIA}

\section{Haemophilus influenzae}

There are two major types of Haemophilus influenzae infections causing significant morbidity and mortality. The pathogen is commonly carried in the pharynx and is a frequent cause of upper respiratory tract infections: after $S$. pneumoniae it is the second most common isolate from acute otitis media cases worldwide. Most of these isolates are nonencapsulated, or express capsular types other than " $b$ ". The majority of invasive infections (meninigitis and pneumonia in particular) are due to strains expressing type "b" capsular antigen (Hib). The incidence of invasive infections has been radically reduced in countries where the conjugated capsular vaccine had been used. Where introduced, the effect of vaccination programs in developing countries has been as successful as in high-income regions [141, 142], although the majority of the under-privileged areas are still far from a satisfactory level of vaccine coverage. Consequently, Hib was still estimated to cause over 8 million serious infections worldwide in 2000, in children under 5 years of age, resulting in an estimated 371,000 death, mostly in low income countries [143]. 
Resistance of $H$. influenzae to beta-lactams is of primary concern all over the world. However, in some developing countries increasing rates of multidrug resistance, nonsusceptibility to trimethoprim/sulfamethoxazole, fluroquinolones, and/or to chloramphenicol are emerging problems. Ampicillin resistance is common due to the production of TEM-1 or ROB-1 type beta lactamases [144, 145]. In a recent study Sham et al. found that in most regions of the world ampicillin resistance was below $20 \%$ and only in Asia and North America it did approach 30\%, while amoxillin/clavulanate resistance remained below $0.5 \%$ globally [68]. Although most of the local studies report similar or lower figures, some found much higher rates of ampicillin resistance, e.g. in Thailand with $48.4 \%$ of the isolates producing beta-lactamase [146], and in another study $37 \%$ ampicillin resistance among the non-typable strains [147]. In Egypt $63 \%$ of ampicillin resistance was found among isolates from meningitis cases [148]. In a recent SENTRY study of strains collected in North and Latin America the rates of ampicillin resistance were more than twice as high as those seen in Europe $(41.2 \%$ and $45.5 \%$ $\left.v_{s} 18.0 \%\right)$ while all strains remained susceptible to amoxicillin/clavulanic acid [149]. In some developing countries there is a clear trend in increasing resistance: among invasive isolates in rural Kenya it was found that from $100 \%$ recorded in 1994, susceptibility to amoxicillin decreased to $32.2 \%$ by 2002. Alarmingly, it was accompanied by a $100 \%$ to $28.1 \%$ decrease in chloramphenicol susceptibility, and by a $66.6 \%$ to $14.8 \%$ decrease in trimethoprim/sulfamethoxazole susceptibility with $40 \%$ of the strains being MDR in 2002 [150].

Recently, a new type of beta-lactam resistance mechanism in $H$. influenzae has emerged, i.e. due to mutations decreasing the affinity of the penicillin binding proteins (PBPs) to the drug [151]. This results in the "beta lactamase nonproducing ampicillin resistant" (BLNAR) phenotype. These strains are found with varying - usually low - frequencies in Europe and in North America, but some Asian countries, particularly Japan, are heavily burdened [152-155]. BLNAR strains with decreased ampicillin susceptibility, but none expressing full resistance, were isolated from lower respiratory infections in children in Vietnam [156]. In North India $14.4 \%$ of the $H$. influenzae strains isolated from the nasopharynx of children were BLNAR (based on the lack of beta-lactamase activity), $81.8 \%$ of which expressed the "b" type capsular antigen. Although no molecular analysis to reveal the genetic basis of BLNAR was done, 9 out of the 33 BLNAR strains were fully resistant to ampicillin. In the same study resistance to chloramphenicol, erythromycin and co-trimoxazole was common, particularly among the beta-lactamase producing strains [157].

Although apparently emerging in some developing countries as well, BLNAR strains are still not uniformly present in Asia. While a high rate of beta lactamase producers among $H$. influenzae were recovered from the nasopharynx of healthy children below 5 years of age, and among isolates from invasive cases $(61,5 \%$ and $55 \%$, respectively). In Taiwan, no BLNAR were isolated [158, $159]$.
The introduction of the PCV7 vaccine in developing countries is likely to increase the frequency of colonization of the upper respiratory tract by $H$. influenzae compared to $S$. pneumoniae. It is also anticipated that this will result in a shift towards the former pathogen as the etiological agent of otitis media, as happened in the developed nations [160]. This, together with increasing rates of BLNAR and MDR strains are likely to bring new challenges for treatment. It will be particularly difficult in countries with limited resources since therapies alternative to simple beta-lactams are often more costly [161]. The changes are affecting treatment options for invasive cases as well.

\section{Neisseria gonorrhoeae}

In 1999, the highest number of new gonorrhea cases occured in South-East Asia (27.2 million) and in subSaharan Africa (17.03 million) [162]. With 1.11 million and 1.56 million new cases in Western Europe and in North America respectively, it is estimated that, all regions considered, the prevalence is at least 10 times higher in the developing world than in the industrialized countries [163].

The speed of emergence and spread of antibiotic resistance in Neisseria gonorrhoeae has been matched by few pathogens only. In the past 25 years, this has enforced repeated changes of paradigms in treatment and it is not unrealistic to expect the need for the next one in the foreseeable future. Following a relatively short lived use of sulfanilamides starting from the $1940 \mathrm{~s}$ penicillin has remained the drug of choice for a long time. However, by the mid $80 \mathrm{~s}$ chromosomal and plasmid-coded resistance mechanisms became wide-spread, frequently co-emerging with tetracycline resistance [164]. Gradually, $3^{\text {rd }}$ generation cephalosporins and fluoroquinolones became the recommended therapies, substantially increasing the costs of treatment. Unfortunately, however, even the relatively cheaper oral fluroquinolones (ciprofloxacin, ofloxacin) became obsolete in the forthcoming decade in most parts of the world. Emerging in the Pacific regions [165] and quickly spreading through Asia and to the rest of the world, fluroquinolone resistant strains have reached very high frequencies adding to the usually wide-spread penicillin and tetracycline resistance all over the world, including developing countries [166-171]. The few localities still experiencing a low rate of ciprofloxacin resitance more likely represent exceptions then the rule $[172,173]$. The emergence of multidrug resistance is favored by the fact that $N$. gonorrhoeae has a tendency to retain resistance, even if the use of the particular drugs has been discontinued [174]. As a result, resistance to multiple antibiotics became a serious challenge in several of these areas [169, 175]. Consequently, current treatment recommendations are restricted to a single class of antibiotics, i.e. cephalosporins, either as an injectable (ceftriaxone) or as an oral (cefixime) drug $[176,177]$.

Limitations of therapeutic options had already seriously challenged the resources of developing countries, while in some countries extended spectrum cephalosporins are not even available for gonorrhea treatment [178]. Meanwhile reports on therapeutic failures following oral (not parenteral, yet) cefixime or ceftibuten treatment have already been increasing, particularly in Asia and in the Pacific Region 
$[179,180]$. In some countries, like Japan, the problem has increased to the extent that oral cefalosporin therapy is not even recommended any longer [181].

Once parenteral, increased dose (i.e. $250 \mathrm{mg}-1 \mathrm{~g}$ ) cefalosporin regimens failed in the future, alternative treatments will be difficult to find. A possible alternative, spectinomycin, is not uniformly available. Currently, even in the developing countries, the overwhelming majority of the strains are still susceptible [166, 168, 169, 172, 180, 182], but resistance, once used extensively, develops easily [183] making the drug an unlikely candidate as the first line treatment. Azithromycin could also be used, but resistance already exists, therefore, it is also unlikely to represent a safe choice in a much feared post-cephalosporin era [164].

\section{Mycobacterium tuberculosis}

Approximately every third person around the globe is infected with Mycobacterium tuberculosis (MTB). According to the latest $\mathrm{WHO}, 13^{\text {th }}$ annual report on the global control of tuberculosis (TB) [184] in 2007, an estimated 9.27 million new active cases of tuberculosis occurred worldwide. The incidence data are heavily distorted towards developing regions of the world: $55 \%$ of the new cases occurred in Asia and $31 \%$ in Africa. The countries with the highest total number of new cases were India (2.0 million) and China (1.3 million). Fifteen percent of all new TB cases were HIV-positive, $79 \%$ of these cases in Africa and $11 \%$ in South-East Asia. Among the 15 countries with the highest estimated TB incidence rates, 13 are in Africa, a phenomenon linked to high rates of HIV co-infection [184].

Antibiotic resistance in M. tuberculosis commonly emerges if the two key elements of anti-TB therapy (i.e. combination of proper drugs and long term treatment) are not strictly observed. Using multiple drugs to treat susceptible cases, theoretically, allows the survival of newly emerging resistant cells only if more than one resistanceconferring mutation occurs simultaneously in the same cell a statistically unlikely event. Furthermore, the combination of different drugs should act at the same time on cells of the pathogen occupying different niches (e.g. cavities, caseous material, intracellular within macrophages) and exhibiting very different levels of metabolic activities. Long exposure to drugs is needed to eradicate cells with limited activity. A pan-susceptible strain gaining resistance during treatment (acquired resistance) usually indicates inadequacies in therapy. The rate of infection with a resistant organism is strongly influenced, beyond the comparative biological fitness, virulence and transmissibility of the resistant strains, by the level of local TB control, i.e. the number of infectious patients in the community, by the number of susceptible individuals etc. [185]. The spectrum of resistance can be broadened if patients infected with strains already resistant to some drugs still receive inappropriate chemotherapy (amplified resistance) [186]. This may contribute to the emergence of multi-drug - (MDR), and extensively resistant strains (XDR), respectively. MDR strains are defined as being resistant to isoniazid and rifampin, while XDR isolates gained further resistance to any fluoroquinolone and to at least one of the three injectable second-line drugs (i.e., amikacin, kanamycin, or capreomycin) [187].
While there are still a few countries not reporting any MDR tuberculosis, which is truly a global problem. The most seriously affected regions are countries of the former Soviet Union and China in particular. The Global Project on Anti-Tuberculosis Drug Resistance Surveillance program recently published its report on drug susceptibility data collected between 2002 and 2007 [188]. In the 75 countries and territories providing figures on new cases of TB, the median prevalence of MDR cases was $1.6 \%$ globally. However, 12 of the 15 locations with MDR prevalence above $6 \%$ were countries of the former Soviet Union and two were Chinese provinces. The highest figures were seen in Baku, Azerbaijan (22.3\%) and Moldova (19.4\%). This distribution was not unlike the one seen for resistance to isoniazid alone: of the 17 settings with a prevalence of isoniazid resistance higher than $15 \%, 14$ were former Soviet territories or located in China [187]. As expected, the median prevalence of MDR tuberculosis among previously treated cases reported from 68 countries was higher than observed among new cases (11.7\%). In this comparison also, countries worst hit were those of the former Soviet Union. Of the 17 locations with MDR prevalence over $25 \%$ (i.e. every fourth case previously having received treatment is an MDR case) 9 were from Soviet republic or its territory. In some of these regions (e.g. Lithuania, Orel Oblast, Tomsk Oblast), an increase in MDR prevalence was observed during the study period. In 8 countries of the former Soviet Union approximately $10 \%$ of the MDR strains were, in fact XDR, with the highest figure (23.7\%) observed in Estonia [188].

An interesting disproportionality was found earlier by Shah et al. [189] collecting data from 14 Supranational Reference Laboratories (SRLs) worldwide on susceptibility tests carried out between 2000 and 2004. While the highest rate of MDR strains among all MTB tested was found in Asia (70.1\%) (excluding South Korea) only $1.52 \%$ of these were XDR. On the other hand, in the Republic of Korea with a comparatively low rate of MDR (10.9\%), a high percentage of these isolates qualified as XDR (15.4\%). The African and Middle Eastern regions provided lower figures than the industrialized nations both in terms of MDR $(23.5 \%$ vs $32.9 \%)$ as well as for XDR $(0.6 \%$ vs $6.5 \%)$, respectively. Although further studies should clarify as to what extent these figures represent dissimilarities in testing and sampling methods or in real prevalences, they ceratinly shed light on the worldwide emerging problem of XDR TB [189].

It should be noted that even these alarming figures are likely to underestimate the problem of the emerging MDR, and in particular of the XDR epidemics. Drug resistance surveillance is seriously hampered in many countries by the technical limitations in the susceptibility testing methods available - facts most likely to affect regions having a higher prevalence of cases [190]. Even if some facilities are there, laboratories may test only one or two second line drugs and may use different methodologies [191].

For the developing countries, particularly in Asia and Africa, it is imperative to gain a better understanding of the association of HIV and MDR-TB. HIV infection clearly facilitates the progression of active diseases following primary infection, and also increases reactivation of latent cases. In both cases microbial load is amplified which is anticipated to increase drug resistant cases [187]. Statistical 
data, on the other hand do not always show a clear correlation between HIV and drug resistance of TB coinfection: in 5 of the 7 regions reporting on the HIV status of MDR TB patients no significant association between MDRTB and HIV infection was found, although none of these regions were from Africa with a high HIV burden [188]. The increased mortality among TB-HIV co-infected patients certainly warrants the extension of isoniazid chemoprophylaxis among those infected with HIV to prevent activation of latent TB, and thus indirectly having a limiting effect on the emergence of MDR cases as well [186].

Preventing the emergence of acquired and amplified resistance requires rapid and accurate diagnosis including susceptibility testing followed by a full-course treatment. Consequently, countries with limited resources are clearly disadvantaged. The DOTS (Direct Observation Treatment, Short course) program of the WHO can be instrumental in this field. Its key targets are to secure global and local political and financial commitments, assuring case detection through quality-assured bacteriology, standardized treatment with supervision and patient support, sustaining effective drug supply and management system, and monitoring evaluation system and impact measurement. Recently, building on the success of this initiative, the program was extended to target MDR case, as well (DOTS-Plus [192]).

However, preventing emergence of drug resistance alone is unlikely to solve the problem of MDR and XDR TB. Increasing number of evidence has shown that transmitted resistance is the primary mechanism for XDR-TB epidemic with $63-75 \%$ of the cases being transmitted in some outbreaks $[190,193]$. Interrupting the chains of transmission in the community as well as in the hospitals with well designed and affordable infection control measures has significant impact on MDR/XDR TB cases. Steps as simple and cheap as increased ventilation or rapid patient isolation in hospital settings [194,195] have a significant impact on MDR/XDR-TB transmission.

\section{FACTORS FAVORING ANTIMICROBIAL RESISTANCE}

Emergence of organisms resistant to antibiotics, either by mutations or by acquiring new genetic material by horizontal gene transfer, takes place irrespective of the presence of antibiotics. It is the exposure to drugs that provides an advantage to cells with the newly gained phenotype and promotes their expansion. Use of antibiotics, as a side effect, also gives rise to resistance - a biological price we have to pay for benefitting from the curative potential of these drugs. However, their excessive or suboptimal use creates excessive resistance - a situation we are currently experiencing all over the world.

The biological driving forces behind the wide-spread drug resistance in the developing countries are, in principle, the same as in high-income countries, only multiplied and accentuated. In these countries internationally developed and accepted guidelines related to susceptibility testing, antibiotic use and infection control may not be broadly available, not to mention the lack of financial constraints to implement them. Furthermore, due to the often lower general educational level of the population these standards are less known, less accepted and appreciated and less expected both by the providers, as well as the receivers of health care.
Underprivileged sub-populations of wealthier countries are affected by the poverty-driven constraints in antibiotic use similar to those commonly seen in developing countries [196].

Several factors favor the development of bacterial resistance to antibiotics in developing countries:

1. Less potent activity: Some of the antibiotics provided in developing countries have decreased potency because of degradation or adulteration of the drug, or because of the presence of a lower concentration of active substances [197-199]. For instance, substandard concentrations of ampicillin and tetracycline have been found in Nigeria [200,201]. Moreover, expired drugs, with altered or removed expiry dates, have also been detected in developing countries [202-204]. Some drugs produced in industrialized countries have been found to have expired on distribution in developing countries [205]. Finally, the antibiotics provided to these countries may be poorly transported and stored, leading to drug inactivation [206-208].

2. Lack of diagnostic laboratories: Most of the hospitals in developing countries do not have clinical microbiology laboratories to perform routine analyses for microbiological diagnosis. Even if some services are in place, international guidelines and quality control for susceptibility testing are often not available or require methods not affordable locally. Therefore, they have no information about either the etiology of the infectious diseases or antimicrobial susceptibility, both essential for clinical practice. Bacterial infections are often treated empirically with broad-spectrum antibiotics. For control, an accurate diagnosis including proper susceptibility data is a must, supplemented with capacities to type organism. This needs properly standardized, quality controlled methods complemented with the collection and compilation of data into appropriate databases on antibiotic resistance. A hierarchical structure of local, national, regional and supranational laboratories with well defined and controlled competences can only meet these tasks.

3. Over-the-counter availability: In most developing countries, antibiotics can be purchased without prescription in pharmacies, general stores, markets, and from street hawkers. Since many drugs are expensive, some patients purchase incomplete regimens whenever possible and discontinue treatment when the symptoms disappear [209]. As in industrialized countries, unnecessary prescriptions of antibiotics, mainly in cases of acute infantile diarrhea and respiratory infections, have been reported in developing countries [210-213]. Although the problem is not exclusive to the developing countries, in many hospitals in these regions antibiotic policies and infection control practices are suboptimal, nonexistent, not appropriately enforced or compromised due to the lack of resources and properly trained personnel [214]. 
4. Use of antimicrobials in animals. Although it may not seem to be an important problem in developing countries, where the practice is less applied, the excessive use of antimicrobials, especially as growth promoters in animals destined for human consumption, presents a growing risk to human health due to the emergence of bacteria resistant to the antibiotics fed to animals, which can then be transferred to humans through the food chain [215217]. Spread of antibiotics and resistant bacteria into the environment is also a contributor to the problem.

In order to improve this situation, a better understanding of the driving forces behind inappropiate demands, medical practices should be well understood, a surprisingly underresearched area in developing countries [218,219]. Basic health education is likely to influence expectations, remove mistrust or correct unfounded believes concerning antibiotics [218]. Improving education among health care providers concerning prudent use of antibiotics will bring the same benefits in the developing countries [220] as has been proven repeatedly in the industrialized world.

Contribution to control the emergence and spread of antibiotic resistance in the developing countries is a gargantuan task, but it is the moral obligation of the industrialized countries to improve the well being of people living in underprivileged conditions. However, as microorganisms do not respect boundaries, it is also an interest of their very own.

\section{REFERENCES}

[1] Nataro JP, Kaper JB. Diarrheagenic Escherichia coli. Clin Microbiol Rev 1998; 11: 142-201.

[2] Vargas M, Gascón J, Gallardo F, et al. Prevalence of diarrheagenic Escherichia coli strains detected by PCR in patients with travelers' diarrhea. Clin Microbiol Infect 1998; 4: 682-8.

[3] Sire JM, Nabeth P, Perrier-Gros-Calude JD, et al. Antimicrobial resistance in outpatient Escherichi coli urinary isolates in Dakar, Senegal. J Infect Dev Ctries 2007; 1: 263-8.

[4] Hima-Lerible H, Ménard D, Talarmin A. Antimicrobial resistance among uropathogens that cause community-acquired urinary tract infections in Bangui, Central African Republic. J Antimicrob Chemother 2003; 51: 192-4.

[5] Kothari A, Sagar V. Antibiotic resistance in pathogens causing community-acquired urinary tract infections in India: a multicenter study. J Infect Dev Ctries 2008; 2: 354-8.

[6] Randrianirina F, Soares JL, Carod JF, et al. Antimicrobial resistance among uropathogens that cause community-acquired urinary tract infections in Antananarivo, Madagascar. J Antimicrob Chemother 2007; 59: 309.

[7] Matute AJ, Hak E, Schurink CAM, et al. Resistance of uropathogens in symptomatic urinary tract infections in León, Nicaragua. Int J Antimicrob Agents 2004; 23: 506-9.

[8] Ahmed AA, Osman H, Mansour AM, et al. Antimicrobial agent resistance in bacterial isolates from patients with diarrhea and urinary tract infection in the Sudan. Am J Trop Med Hyg 2000; 63: 259-63.

[9] Hirakata Y, Matsuda J, Miyazaki Y, et al. Regional variation in the prevalence of extended-spectrum $\beta$-lactamase-producing clinical isolates in the Asia-Pacific region (SENTRY 1998-2002). Diagn Microbiol Infect Dis 2005; 52: 323-9.

[10] Qadri F, Svennerholm AM, Faruque ASG, Sack RB. Enterotoxigenic Escherichia coli in developing countries: Epidemiology, microbiology, clinical features, treatment and prevention. Clin Microbiol Rev 2005; 18: 465-83.

[11] Rao MR, Abu-Elyazeed R, Savarino SJ, et al. High disease burden of diarrhea due to enterotoxigenic Escherichia coli among rural Egyptian infants and young children. J Clin Microbiol 2003; 41: 4862-4.
[12] Vila J, Vargas M, Casals C, et al. Antimicrobial resistance of diarrheagenic Escherichia coli isolated from children under the age of 5 years from Ifakara, Tanzania. Antimicrob Agents Chemother 1999; 43: 3022-4.

[13] Rowland MG. The Gambia and Bangladesh-the seasons and diarrhoea. Dialogue Diarrhoea 1986; (26): 3.

[14] Echevarria P, Verhaert L, Ulyangco CV, et al. Antimicrobial resistance and enterotoxin production among isolates of Escherichia coli in the Far East. Lancet 1978; ii: 589-92.

[15] Martínez L, Arenas MM, Montes MY, Martínez LJ, Baca BE. Antibiotic resistance and plasmid pattern of enterotoxigenic ST-a strains of Escherichia coli isolated in Puebla, Mexico. Can J Microbiol 1987; 33: 816-9.

[16] Isenbarger DW, Hoge CW, Srijan A, et al. Comparative antibiotic resistance of diarrheal pathogens from Vietnam and Thailand, 1996-1999. Emerg Infect Dis 2002; 8: 175-80.

[17] Mendez-Arancibia E, Pitart C, Ruiz J, Marco F, Gascón J, Vila J. Evolution of antimicrobial resistance in enteroaggregative Escherichia coli and enterotoxigenic Escherichia coli causing traveller's diarrhoea. J Antimicrob Chemother 2009; 64: 343-7.

[18] Nataro JP, Kaper JB, Robins-Browne R et al. Pattterns of adherence of diarrheagenic Escherichia coli to Hep-2 cells. Pediatr Infect Dis J 1987; 6: 829-31.

[19] Mendez-Arancibia E, Vargas M, Soto S, et al. Prevalence of different virulence factors and biofilm production in enteroaggregative Escherichia coli isolates causing diarrhea in children in Ifakara (Tanzania). Am J Trop Med Hyg 2008; 78: 9859 .

[20] Vargas M, Gascón J, Casals C, et al. Etiology of diarrhea in children less than five years of age in Ifakara, Tanzania. Am J Trop Med Hyg 2004; 70: 536-9.

[21] Sang WK, Oundo JO, Mwituria JK, et al. Multidrug-resistant enteroaggregative Escherichia coli associated with persistent diarrhea in Kenyan children. Emerg Infect Dis 1997; 3: 373-4.

[22] Okeke IN, Lamikanra A, Czeczulin J, et al. Heterogeneous virulence of enteroaggregative Escherichia coli strains isolated from children in Southwest Nigeria. J Infect Dis 2000; 181: 252-60.

[23] Yamamoto T, Echeverria P, Yokota T. Drug resistance and adherence to human intestines of enteroaggregative Escherichia coli. J Infect Dis 1992; 165: 744-9.

[24] Sonnevend A, Al Dhaheri K, Mag T, et al. T. CTX-M-15 producing multidrug resistant enteroaggregative Escherichia coli in the United Arabs Emirates. Clin Microbial Infect 2006; 12: 582-5.

[25] Torres ME, Pirez MC, Schelotto F, et al. Etiology of children's diarrhea in Montevideo, Uruguay: associated pathogens and unusual isolates. J Clin Microbiol 2001; 39: 2134-9.

[26] Ekdahl K, Andersson Y. The epidemiology of travel-associated shigellosis - regional risks, seasonality and serogroups. J Infect 2005; 51: 222-9.

[27] Lima AAM, Lima NL, Pinho MCN, et al. High frequency of strains multiply resistant to ampicillin, trimethoprimsulfamethoxazole, streptomycin, chloramphenicol, and tetracycline isolated from patients with shigellosis in Northeastern Brazil during the period 1988 to 1993. Antimicrob Agents Chemother 1995; 39: 256-9.

[28] Dutta S, Sinha T, Dutta P. Serotypes and antimicrobial susceptibility patterns of Shigella species isolated from children in Calcutta, India. Eur J Clin Microbiol Infect Dis 1998; 17: 298-9.

[29] Tjaniadi P, Lesmana M, Subekti D, et al. Antimicrobial resistance of bacterial pathogens associated with diarrheal patients in Indonesia. Am J Trop Med Hyg 2003; 68: 666-70.

[30] Brooks JT, Chieng JB, Kumar L, et al. Surveillance for bacterial diarrhea and antimicrobial resistance in rural Western Kenya, 1997-2003. Clin Infect Dis 2006; 43: 393-401.

[31] Bogaerts J, Verhaegen J, Munyabikali JP, et al. Antimicrobial resistance and serotypes of Shigella isolates in Kigali, Rwanda (1983 to 1993): increasing frequency of multiple resistance. Diagn Microbiol Infect Dis 1997; 28: 165-71.

[32] Navia MM, Capitano L, Ruiz J, et al. Typing and characterization of mechanisms of resistance of Shigella spp isolated from feces of children under 5 years of age from Ifakara, Tanzania. J Clin Microbiol 1999; 37: 3113-7.

[33] Nguyen TV, Le PV, Weintraub A. Antibiotic resistance in diarrheagenic Escherichia coli and Shigella strains isolated from children in Hanoi, Vietnam. Antimicrob Agents Chemother 2005; 49: 816-9. 
[34] Lee JC, Oh JY, Kim KS, et al. Antimicrobial resistance of Shigella sonnei in Korea during the last two decades. APMIS 2001; 109: 228-34.

[35] Ries AA, Wells JG, Olivola MD, et al. Epidemic Shigella dysenteriae type 1 in Burundi: panresistance and implications for prevention. J Infect Dis 1994; 169: 1035-41.

[36] Mensa L, Marco F, Vila J, Gascón J, Ruiz J. Quinolone resistance among Shigella spp. Isolated from travellers returning from India. Clin Microbiol Infect 2008; 14: 279-81.

[37] Fàbrega A, du Merle L, Le Bouguénec C, Jimenez de Anta MT, Vila J. Repression of invasion genes and decreased invasion in a high-level fluoroquinolone-resistant Salmonella Typhimurium mutant. PLoS One 2009: 4: e8029.

[38] Cook E. Salmonella species (including typhoid fever). In Mandell GL, Douglas RG, Bennet JE, Eds. Principles and practices of infectious diseases. Churchill Livingston: New York 1990; pp. 1700-15.

[39] Murray BE. Resistance of Shigella, Salmonella, and other selected enteric pathogens to antimicrobial agents. Rev Infect Dis 1986; 8(Suppl 2): S172-81.

[40] Peirano G, Agerso Y, Aarestrup FM, Falavina dos Reis EM, dos Prazeres Rodriguez D. Ocurrence of integrons and antimicrobial resistance genes among Salmonella enterica from Brazil. J Antimicrob Chemother 2006; 58: 305-9.

[41] Ammari S, Laglaoui A, En-nanei L, et al. Isolation, drug resistance and molecular characterization of Salmonella isolates in northern Morocco. J Infect Dev Ctries 2009; 3: 41-9.

[42] Lee HY, Su LH, Tsai MH, et al. High rate of reduced susceptibility to ciprofloxacin and ceftriaxone among nontyphoid Salmonella clinical isolates in Asia. Antimicrob Agents Chemother 2009; 53: 2696-9.

[43] Salazar-Lindo E, Sack RB, Chea-Woo E, et al. Early treatment with erythromycin of Campylobacter jejuni-associated dysentery in children. J Pediatr 1986; 109: 355-60.

[44] Trofa KAF, Thomas RJ. Use of azithromycin for the treatment of Campylobacter enteritis in travellers to Thailand, an area where ciprofloxacin resistance is prevalent. Clin Infect Dis 1995; 21: 53641.

[45] Goosens H, DeMol P, Coignan $\mathrm{H}$ et al. Comparative in vitro activities of aztreonam, ciprofloxacin, norfloxacin, ofloxacin, HR 810 ( a new cephalosporin), RU 28965 ( a new macrolide) and other agents against enteropathogens. Antimicrob Agents Chemother 1985; 27: 388-92.

[46] Ruiz J, Marco F, Oliveira I, Gascón J, Vila J. trends in antimicrobial resistance in Campylobacter spp. Causing traveler's diarrhea. APMIS 2007; 115: 218-24.

[47] Galanis E. Campylobacter and bacterial gastroenteritis. Can Med Assoc J 2007; 177: 570-1.

[48] Dalsgaard A, Forslund A, Sandvang D, Arntzen L, Keddy K. Vibrio cholerae O1 outbreak isolates in Mozambique and South Africa in 1998 are multi-drug resistant, contain the sxt element and the aadA2 gene located on class 1 integron. J Antimicrob Chemother 2001; 48: 827-38.

[49] Das S, Saha R, Kaur IR. Trend of antibiotic resistance of $V$. cholerae strains from East Delhi. Indian J Med Res 2008; 127: 47882.

[50] Garg P, Sinha S, Chakraborty R, et al. Emergence of fluoroquinolone-resistant strains of Vibrio cholerae O1 biotype El Tor among hospitalized patients with cholera in Calcutta, India. Antimicrob Agents Chemother 2001; 45: 1605-6.

[51] Figueras MJ. Clinical relevance of Aeromonas. Rev Med Microbiol 2005; 16: 145-53.

[52] Taneja N, Khurana S, Trehan A, Marwaha RK, Sharma M. Na outbreak of hospital acquired diarrhea due to Aeromonas sobria. Indian Pediatr 2004; 41: 912-6.

[53] Ghenghesh KS, Ahmed SF, El-Khalek RA, Al-Gendy A, Klena J. Aeromonas-associated infections in developing countries. J Infect Dev Ctries 2008; 2: 81-98.

[54] Stock I, Wiedemann B. Natural antimicrobial susceptibilities of Plesiomonas shigelloides strains. J Antimicrob Chemother 2001; 48: 803-11.

[55] Lagamayo EN. Antimicrobial resistance in major pathogens of hospital-acquired pneumonia in Asian countries. Am J Infect Control 2008; 36: S101-8.

[56] Ndip RN, Dilonga HM, Ndip LM, Akoachere JFK, Akeujit N. $P$. aeruginosa isolates recovered from clinical and environmental samples in Nuea, Cameroon: Current status on biotyping and antibiogram. Trop Med Int Health 2005; 10: 74-81.

[57] Andrade SS, Jones RN, Gales AC, Sader HS. Increasing prevalence of antimicrobial resistance among P. aeruginosa isolates in Latin American medical centres: 5 year report of the SENTRY antimicrobial surveillance program (1997-2001). J Antimicrob Chemother 2003; 52: 140-1.

[58] Lee K, Park KH, Jeong SH, et al. Further increase of vancomycinresistant Enterococcus faecium, amikacin- and fluoroquinoloneresistan Klebsiella pneumoniae, and imipenem-resistant Acinetobacter species in Korea: 2003 KONSAR Surveillance. Yonsei Med J 2006; 47: 43-54.

[59] Singh AK, Sen MR, Anapurba S, Bhattacharya P. Antibiotic sensitivity pattern of the bacteria isolated from nosocomial infections in ICU. J Commun Dis 2002; 34: 257-63.

[60] Pachon J, Vila J. Treatment of multiresistant Acinetobacter baumannii infections. Curr Opin Invest Drugs 2009; 10: 150-6.

[61] Higgins PG, Dammhayn C, Hackel M, Seifert H. Global spread of carbapenem-resistant Acinetobacter baumannii. J Antimicrob Chemother 2010; 65(2): 233-8.

[62] O'Brien KL, Wolfson LJ, Watt JP, et al. Hib and Pneumococcal Global Burden of Disease Study Team. Burden of disease caused by Streptococcus pneumoniae in children younger than 5 years: global estimates. Lancet 2009; 374: 893-902.

[63] American Academy of Pediatrics Subcommittee on Management of Acute Otitis Media. Diagnosis and management of acute otitis media. Pediatrics 2004; 113: 1451-65.

[64] Rodgers GL, Arguedas A, Cohen R, Dagan R. Global serotype distribution among Streptococcus pneumoniae isolates causing otitis media in children: potential implications for pneumococcal conjugate vaccines. Vaccine 2009; 27: 3802-10.

[65] Clinical and Laboratory Standards Institute. Performance standards for antimicrobial susceptibility testing. Eighteenth informational supplement. Document M100-S18. Wayne, PA: CLSI 2008.

[66] Hsieh YC, Lin PY, Chiu CH, et al. National survey of invasive pneumococcal diseases in Taiwan under partial PCV7 vaccination in 2007: emergence of serotype 19A with high invasive potential. Vaccine 2009; 27: 5513-8.

[67] Felmingham D, Cantón R, Jenkins SG. Regional trends in betalactam, macrolide, fluoroquinolone and telithromycin resistance among Streptococcus pneumoniae isolates 2001-2004. J Infect 2007; 55: 111-8.

[68] Sahm DF, Brown NP, Thornsberry C, Jones ME. Antimicrobial susceptibility profiles among common respiratory tract pathogens: a GLOBAL perspective. Postgrad Med 2008; 120(Suppl 1): 16-24.

[69] Castanheira M, Gales AC, Mendes RE, Jones RN, Sader HS. Antimicrobial susceptibility of Streptococcus pneumoniae in Latin America: results from five years of the SENTRY Antimicrobial Surveillance Program. Clin Microbiol Infect 2004; 10: 645-51.

[70] Camargos P, Fischer GB, Mocelin H, Dias C, Ruvinsky R. Penicillin resistanceand serotyping of Streptococcus pneumoniae in Latin America. Paediatr Respir Rev 2006; 7: 209-14.

[71] Vlieghe E, Phoba MF, Tamfun JJ, Jacobs J. Antibiotic resistance among bacterial pathogens in Central Africa: a review of the published literature between 1955 and 2008. Int J Antimicrob Agents 2009; 34: 295-303.

[72] Mudhune S, Wamae M. Network Surveillance for Pneumococcal Disease in the East African Region. Report on invasive disease and meningitis due to Haemophilus influenzae and Streptococcus pneumonia from the Network for Surveillance of Pneumococcal Disease in the East African Region. Clin Infect Dis 2009; 48(Suppl 2): S147-52.

[73] Hill PC, Onyeama CO, Ikumapayi UN, et al. Bacteraemia in patients admitted to an urban hospital in West Africa. BMC Infect Dis 2007; 7: 2 .

[74] Borg MA, Tiemersma E, Scicluna E, et al. Prevalence of penicillin and erythromycin resistance among invasive Streptococcus pneumoniae isolates reported by laboratories in the southern and eastern Mediterranean region. Clin Microbiol Infect 2009; 15: 2327.

[75] Memish ZA, Balkhy HH, Shibl AM, Barrozo CP, Gray GC. Streptococcus pneumoniae in Saudi Arabia: antibiotic resistance and serotypes of recent clinical isolates. Int J Antimicrob Agents 2004; 23: 32-8

[76] Senok A, Al-Zarouni M, Al-Najjar J, Nublusi A, Panigrahi D. Antimicrobial resistance among Streptococcus pneumoniae and 
Haemophilus influenzae isolates in the United Arab Emirates: 2004-2006. J Infect Dev Ctries 2007; 1: 296-302.

[77] Shibl A, Memish Z, Pelton S. Epidemiology of invasive pneumococcal disease in the Arabian Peninsula and Egypt. Int $\mathrm{J}$ Antimicrob Agents 2009; 33: 410. e1-9.

[78] Song JH, Jung SI, Ko KS, et al. High prevalence of antimicrobial resistance among clinical Streptococcus pneumoniae isolates in Asia (an ANSORP study). Antimicrob Agents Chemother 2004; 48: 2101-7.

[79] Liu Y, Wang $\mathrm{H}$, Chen $\mathrm{M}$, et al. Serotype distribution and antimicrobial resistance patterns of Streptococcus pneumoniae isolated from children in China younger than 5 years. Diagn Microbiol Infect Dis 2008; 61: 256-63.

[80] Bravo LC, Asian Strategic Alliance for Pneumococcal Disease Prevention (ASAP) Working Group Overview of the disease burden of invasive pneumococcal disease in Asia. Vaccine 2009; 27: 7282-91

[81] Farrell DJ, Couturier C, Hryniewicz W. Distribution and antibacterial susceptibility of macrolide resistance genotypes in Streptococcus pneumoniae: PROTEKT Year 5 (2003-2004). Int J Antimicrob Agents 2008; 31: 245-9.

[82] Wolter N, von Gottberg A, du Plessis M, de Gouveia L, Klugman KP. Group for Enteric, Respiratory and Meningeal Disease Surveillance in South Africa. Molecular basis and clonal nature of increasing pneumococcal macrolide resistance in South Africa, 2000-2005. Int J Antimicrob Agents 2008; 32: 62-7.

[83] Dagan R, Klugman KP. Impact of conjugate pneumococcal vaccines on antibiotic resistance. Lancet Infect Dis 2008; 8: 78595.

[84] Picazo JJ. Management of antibiotic-resistant Streptococcus pneumoniae infections and the use of pneumococcal conjugate vaccines. Clin Microbiol Infect 2009; 15(Suppl 3): 4-6.

[85] Kyaw MH, Lynfield R, Schaffner W, et al. Active Bacterial Core Surveillance of the Emerging Infections Program Network. Effect of introduction of the pneumococcal conjugate vaccine on drugresistant Streptococcus pneumoniae. N Engl J Med 2006; 354 : 1455-63.

[86] Lucero MG, Dulalia VE, Nillos LT, et al. Pneumococcal conjugate vaccines for preventing vaccine-type invasive pneumococcal disease and X-ray defined pneumonia in children less than two years of age. Cochrane Database Syst Rev 2009; 4: CD004977.

[87] World Health Organization Pneumococcal conjugate vaccine for childhood immunization-WHO position paper. Wkly Epidemiol Rec 2007; 82: 93-104.

[88] Cheung YB, Zaman SM, Nsekpong ED, et al. Nasopharyngeal Carriage of Streptococcus pneumoniae in Gambian Children who Participated in a 9-valent Pneumococcal Conjugate Vaccine Trial and in Their Younger Siblings. Pediatr Infect Dis J 2009; 28: 9905.

[89] Hsieh YC, Wang JT, Lee WS, et al. Serotype competence and penicillin resistance in Streptococcus pneumoniae. Emerg Infect Dis 2006; 12: 1709-14.

[90] Reinert RR. The antimicrobial resistance profile of Streptococcus pneumoniae. Clin Microbiol Infect 2009; 15(Suppl 3): 7-11.

[91] Choi EH, Kim SH, Eun BW, et al. Streptococcus pneumoniae serotype 19A in children, South Korea. Emerg Infect Dis 2008; 14 : 275-81.

[92] Antonio M, Dada-Adegbola H, Biney E, et al. Molecular epidemiology of pneumococci obtained from Gambian children aged 2-29 months with invasive pneumococcal disease during a trial of a 9-valent pneumococcal conjugate vaccine. BMC Infect Dis 2008; 8: 81 .

[93] Arifeen SE, Saha SK, Rahman S, et al. Invasive pneumococcal disease among children in rural Bangladesh: results from a population-based surveillance. Clin Infect Dis 2009; 48(Suppl 2): S103-S13.

[94] Rosenthal VD, Maki DG, Mehta A, et al. International Nosocomial Infection Control Consortium Members. International Nosocomial Infection Control Consortium report, data summary for 2002-2007, issued January 2008. Am J Infect Control 2008; 36: 627-37.

[95] Sood S, Malhotra M, Das BK, Kapil A. Enterococcal infections \& antimicrobial resistance. Indian J Med Res 2008; 128: 111-21.

[96] Ergani-Ozcan A, Naas T, Baysan BO, et al. Nosocomial outbreak of vancomycin-resistant Enterococcus faecium in a paediatric unit at a Turkish university hospital. J Antimicrob Chemother 2008; 61: 1033-9.
[97] Zubaidah AW, Ariza A, Azmi S. Hospital-acquired vancomycinresistant enterococci: now appearing in Kuala Lumpur Hospital. Med J Malaysia 2006; 61: 487-9.

[98] Ghoshal U, Garg A, Tiwari DP, Ayyagari A. Emerging vancomycin resistance in enterococci in India. Indian J Pathol Microbiol 2006; 49: 620-2.

[99] Jeric PE, Azpiroz A, Lopardo H, Centrón D. Survey of molecular determinants in Gram-positive cocci isolated from hospital settings in Argentina. J Infect Dev Ctries 2007; 1: 275-83.

[100] Cuellar-Rodríguez J, Galindo-Fraga A, Guevara V, et al. Vancomycin-resistant enterococci, Mexico City. Emerg Infect Dis 2007; 13: 798-9.

[101] McCarthy KM, Van Nierop W, Duse A, et al. Control of an outbreak of vancomycin-resistant Enterococcus faecium in an oncology ward in South Africa: effective use of limited resources. J Hosp Infect 2000; 44: 294-300.

[102] Biedenbach DJ, Bell JM, Sader HS, Fritsche TR, Jones RN, Turnidge JD. Antimicrobial susceptibility of Gram-positive bacterial isolates from the Asia-Pacific region and an in vitro evaluation of the bactericidal activity of daptomycin, vancomycin, and teicoplanin: a SENTRY Program Report (2003-2004). Int J Antimicrob Agents 2007; 30: 143-9.

[103] Emaneini M, Aligholi M, Aminshahi M. Characterization of glycopeptides, aminoglycosides and macrolide resistance among Enterococcus faecalis and Enterococcus faecium isolates from hospitals in Tehran. Pol J Microbiol 2008; 57: 173-8.

[104] Rattanaumpawan P, Thamlikitkul V, Chokepaibulkit K, Lohsiriwat D, Aswapokee N. Vancomycin overuse in Siriraj Hospital. J Med Assoc Thai 2006; 89(Suppl 5): S125-S32.

[105] McCarthy KM, Van Nierop W, Duse A, et al. Control of an outbreak of vancomycin-resistant Enterococcus faecium in an oncology ward in South Africa: effective use of limited resources. J Hosp Infect 2000; 44: 294-300.

[106] Willems RJ, Top J, van Santen M, et al. Global spread of vancomycin-resistant Enterococcus faecium from distinct nosocomial genetic complex. Emerg Infect Dis 2005; 11: 821-8.

[107] Zhu X, Zheng B, Wang S, et al. Molecular characterisation of outbreak-related strains of vancomycin-resistant Enterococcus faecium from an intensive care unit in Beijing, China. J Hosp Infect 2009; 72: 147-54.

[108] Shin JW, Yong D, Kim MS, et al. Sudden increase of vancomycinresistant enterococcal infections in a Korean tertiary care hospital: possible consequences of increased use of oral vancomycin. J Infect Chemother 2003; 9: 62-7.

[109] Singh BR. Prevalence of vancomycin resistance and multiple drug resistance in enterococci in equids in North India. J Infect Dev Ctries 2009; 3: 498-503.

[110] Hahn W, Morley CP, Morrow C, Epling JW. The effect of media attention on concern for and medical management of methicillinresistant Staphylococcus aureus: a multimethod study. J Public Health Manage Pract 2009; 15: 150-9.

[111] Nickerson EK, Hongsuwan M, Limmathurotsakul D, et al. Staphylococcus aureus bacteraemia in a tropical setting: patient outcome and impact of antibiotic resistance. PLoS One 2009; 4: e4308.

[112] Nickerson EK, West TE, Day NP, Peacock SJ. Staphylococcus aureus disease and drug resistance in resource-limited countries in south and east Asia. Lancet Infect Dis 2009; 9: 130-5.

[113] Randrianirina F, Soares JL, Ratsima E, et al. In vitro activities of 18 antimicrobial agents against Staphylococcus aureus isolates from the Institut Pasteur of Madagascar. Ann Clin Microbiol Antimicrob 2007; 6: 5.

[114] Vergnano S, Sharland M, Kazembe P, Mwansambo C, Heath PT. Neonatal sepsis: an international perspective. Arch Dis Child Fetal Neonatal Ed 2005; 90: F220-4.

[115] Osrin D, Vergnano S, Costello A. Serious bacterial infections in newborn infants in developing countries. Curr Opin Infect Dis 2004; 17: 217-24.

[116] Kesah C, Ben Redjeb S, Odugbemi TO, et al. Prevalence of methicillin-resistant Staphylococcus aureus in eight African hospitals and Malta. Clin Microbiol Infect 2003; 9: 153-6.

[117] Orrett FA, Land M. Methicillin-resistant Staphylococcus aureus prevalence: current susceptibility patterns in Trinidad. BMC Infect Dis 2006; 6: 83 . 
[118] Mehndiratta PL, Vidhani S, Mathur MD. A study on Staphylococcus aureus strains submitted to a reference laboratory. Indian J Med Res 2001; 114: 90-4.

[119] Anapurba S, Sen MR. Prevalence of methicillin resistant Staphylococcus aureus in a tertiary referral hospital in eastern Uttar Pradesh. Ind J Med Microbiol 2003; 21: 49-51.

[120] Khan AU, Sultan A, Tyagi A, et al. Amplification of mecA gene in multi-drug resistant Staphylococcus aureus strains from hospital personnel. BMC Infect Dis 2007; 1: 289-95.

[121] Ko KS, Lee YJ, Suh JY, et al. Distribution of major genotypes among methicillin-resistant Staphylococcus aureus clones in Asian countries. J Clin Microbiol 2005; 43: 421-6.

[122] Chongtrakool, P, Ito T, Ma XX, et al. Staphylococcal cassette chromosome mec (SCCmec) typing of methicillinresistant Staphylococcus aureus strains isolated in 11 Asian countries: a proposal for a new nomenclature for SCCmec elements. Antimicrob Agents Chemother 2006; 50: 1001-12.

[123] Witte W, Cuny C, Klare I, Nübel U, Strommenger B, Werner G. Emergence and spread of antibiotic-resistant Gram-positive bacterial pathogens. Int J Med Microbiol 2008; 298: 365-77.

[124] Shittu A, Nübel U, Udo E, Lin J, Gaogakwe S. Characterization of meticillin-resistant Staphylococcus aureus isolates from hospitals in KwaZulu-Natal province, Republic of South Africa. J Med Microbiol 2009; 58: 1219-26.

[125] Gadepalli R, Dhawan B, Kapil A, et al. Clinical and molecular characteristics of nosocomial meticillin-resistant Staphylococcus aureus skin and soft tissue isolates from three Indian hospitals. 2009; 73: 253-63.

[126] Nickerson EK, Wuthiekanun V, Day NP, Chaowagul W, Peacock SJ. Meticillin-resistant Staphylococcus aureus in rural Asia. Lancet Infect Dis 2006; 6: 70-1.

[127] Nickerson EK, Wuthiekanun V, Wongsuvan G, et al. Factors predicting and reducing mortality in patients with invasive Staphylococcus aureus disease in a developing country. PLoS One 2009b; 4(8): e6512.

[128] Thaver D, Ali SA, Zaidi AK. Antimicrobial resistance among neonatal pathogens in developing countries. Pediatr Infect Dis J 2009; 28(1 Suppl): S19-21.

[129] Brown PD, Ngeno C. Antimicrobial resistance in clinical isolates of Staphylococcus aureus from hospital and community sources in southern Jamaica. Int J Infect Dis 2007; 11: 220-5.

[130] Onipede AO, Onayade AA, Elusiyan JB, et al. Invasive bacteria isolates from children with severe infections in a Nigerian hospital. J Infect Dev Ctries 2009; 3: 429-36.

[131] Nagaraju U, Bhat G, Kuruvila M, Pai GS, Jayalakshmi Babu RP. Methicillin-resistant Staphylococcus aureus in community-acquired pyoderma. Int J Dermatol 2004; 43: 412-14.

[132] Baranwal AK, Singh M, Marwaha RK, Kumar L. Empyema thoracis: a 10-year comparative review of hospitalised children from south Asia. Arch Dis Child 2003; 88: 1009-14.

[133] Krishna BV, Patil AB, Chandrasekhar MR. Community-acquired methicillin-resistant Staphylococcus aureus infections in a south Indian city. Southeast Asian J Trop Med Public Health 2004; 35: 371-74.

[134] Sakoulas G, Moellering RC Jr. Increasing antibiotic resistance among methicillin-resistant Staphylococcus aureus strains. Clin Infect Dis 2008; 46(Suppl 5): S360-S7.

[135] Orrett FA. The emergence of mupirocin resistance among clinical isolates of methicillin-resistant Staphylococcus aureus in Trinidad: a first report. Jpn J Infect Dis 2008; 61: 107-10.

[136] Udo EE, Jacob LE, Mathew B. The spread of a mupirocinresistant/methicillin-resistant Staphylococcus aureus clone in Kuwait hospitals. Acta Trop 2001; 80: 155-61.

[137] Song JH, Hiramatsu K, Suh JY, et al. Asian Network for Surveillance of Resistant Pathogens Study Group. Emergence in Asian countries of Staphylococcus aureus with reduced susceptibility to vancomycin. Antimicrob Agents Chemother 2004; 48: 4926-8.

[138] Sun W, Chen H, Liu Y, et al. Prevalence and characterization of heterogeneous vancomycin-intermediate Staphylococcus aureus isolates from 14 cities in China. Antimicrob Agents Chemother 2009; 53: 3642-9.

[139] Lulitanond A, Engchanil C, Chaimanee P, Vorachit M, Ito T, Hiramatsu K. The first vancomycin-intermediate Staphylococcus aureus strains isolated from patients in Thailand. J Clin Microbiol 2009; 47: 2311-6.
[140] Tiwari HK, Sen MR. Emergence of vancomycin resistant Staphylococcus aureus (VRSA) from a tertiary care hospital from northern part of India. BMC Infect Dis 2006; 6: 156.

[141] Adegbola RA, Secka O, Lahai G, et al. Elimination of Haemophilus influenzae type $b(\mathrm{Hib})$ disease from The Gambia after the introduction of routine immunisation with a Hib conjugate vaccine: a prospective study. Lancet $2005 ; 366: 144-50$.

[142] Lewis RF, Kisakye A, Gessner BD, et al. A. Action for child survival: elimination of Haemophilus influenzae type $\mathrm{b}$ meningitis in Uganda. Bull World Health Organ 2008; 86: 292-301.

[143] Watt JP, Wolfson LJ, O'Brien KL, et al. Hib and Pneumococcal Global Burden of Disease Study Team. Burden of disease caused by Haemophilus influenzae type $b$ in children younger than 5 years: global estimates. Lancet 2009; 374: 903-11.

[144] Reid AJ, Simpson IN, Harper PB, Amyes SG. Ampicillin resistance in Haemophilus influenzae: identification of resistance mechanisms. J Antimicrob Chemother 1987; 20: 645-56.

[145] Vega R, Sadoff HL, Patterson MJ. Mechanisms of ampicillin resistance in Haemophilus influenzae type B. Antimicrob Agents Chemother 1976; 9: 164-8.

[146] Srifuengfung S, Chayakulkeeree M, Chokephaibulkit K, Tribuddharat C. Five-year study of antimicrobial susceptibility and betalactamase production in Haemophilus influenzae. Southeast Asian J Trop Med Public Health 2007; 38: 732-6.

[147] Kunthalert D, Thunyathada PK, Pruksakorn S. Phenotypic and genetic characterizations of nontypeable Haemophilus influenzae isolates in a hospital in Thailand. J Infect 2009; 59: 293-6.

[148] Youssef FG, El-Sakka H, Azab A, et al. Antimicrobial susceptibility profiles, and mortality associated with bacterial meningitis among children in Egypt. Ann Epidemiol 2004; 14: 448.

[149] Fedler KA, Biedenbach DJ, Jones RN. Assessment of pathogen frequency and resistance patterns among pediatric patient isolates: report from the 2004 SENTRY Antimicrobial Surveillance Program on 3 continents. Diagn Microbiol Infect Dis 2006; 56: $427-36$.

[150] Scott JA, Mwarumba S, Ngetsa C, et al. Progressive increase in antimicrobial resistance among invasive isolates of Haemophilus influenzae obtained from children admitted to a hospital in Kilifi, Kenya, from 1994 to 2002. Antimicrob Agents Chemother 2005; 49: 3021-4.

[151] Mendelman PM, Chaffin DO, Kalaitzoglou G. Penicillin-binding proteins and ampicillin resistance in Haemophilus influenzae. J Antimicrob Chemother 1990; 25: 525-34.

[152] Hasegawa K, Chiba N, Kobayashi R, et al. Rapidly increasing prevalence of beta-lactamase-nonproducing, ampicillin-resistant Haemophilus influenzae type $\mathrm{b}$ in patients with meningitis. Antimicrob Agents Chemother 2004; 48: 1509-14.

[153] Hasegawa K, Yamamoto K, Chiba N, et al. Diversity of ampicillinresistance genes in Haemophilus influenzae in Japan and the United States. Microbiol Drug Resist 2003; 9: 39-46.

[154] Jansen WT, Verel A, Beitsma M, Verhoef J, Milatovic D. Surveillance study of the susceptibility of Haemophilus influenzae to various antibacterial agents in Europe and Canada. Curr Med Res Opin 2008; 24: 2853-61.

[155] Niki Y, Hanaki H, Yagisawa M, et al. Japanese Society of Chemotherapy. The first nationwide surveillance of bacterial respiratory pathogens conducted by the Japanese Society of Chemotherapy. Part 1: a general view of antibacterial susceptibility. J Infect Chemother 2008; 14: 279-90.

[156] Gotoh K, Qin L, Watanabe K, et al. Prevalence of Haemophilus influenza with resistant genes isolated from young children with acute lower respiratory tract infections in Nha Trang, Vietnam. J Infect Chemother 2008; 14: 349-53.

[157] Jain A, Kumar P, Agarwal SK. High nasopharyngeal carriage of beta-lactamase-negative ampicillin-resistant Haemophilus influenzae in north Indian school-going children. J Infect Chemother 2008; 14: 72-4.

[158] Wang SR, Lo WT, Chou CY, et al. Low rate of nasopharyngeal carriage and high rate of ampicillin resistance for Haemophilus influenzae among healthy children younger than 5 years old in northern Taiwan. J Microbiol Immunol Infect 2008; 41: 32-40.

[159] Jean SS, Hsueh PR, Lee WS, et al. Nationwide surveillance of antimicrobial resistance among Haemophilus influenzae and Streptococcus pneumoniae in intensive care units in Taiwan. Eur J Clin Microbiol Infect Dis 2009; 28: 1013-7. 
[160] Brook I. Current issues in the management of acute bacterial sinusitis in children. Int J Pediatr Otorhinolaryngol 2007; 71: 165361.

[161] Yamanaka N, Hotomi M, Billal DS. Clinical bacteriology and immunology in acute otitis media in children. J Infect Chemother 2008; 14: 180-7.

[162] WHO. Global prevalence and incidence of selected curable sexually transmitted infections: overview and estimates WHO. Geneva 2001.

[163] Gerbase AC, Rowley JT, Heymann DH, Berkley SF, Piot P. Global prevalence and incidence estimates of selected curable STDs. Sex Transm Infect 1998; 74(Suppl 1): S12-6.

[164] Workowski KA, Berman SM, Douglas JM Jr. Emerging antimicrobial resistance in Neisseria gonorrhoeae: urgent need to strengthen prevention strategies. Ann Intern Med 2008; 148: 60613.

[165] Iverson CJ, Wang SA, Lee MV, et al. Fluoroquinolone resistance among Neisseria gonorrhoeae isolates in Hawaii, 1990-2000: role of foreign importation and increasing endemic spread. Sex Transm Dis 2004; 31: 702-8.

[166] Su X, Jiang F, Qimuge Dai X, Sun H, Ye S. Surveillance of antimicrobial susceptibilities in Neisseria gonorrhoeae in Nanjing, China, 1999-2006. Sex Transm Dis 2007; 34: 995-9.

[167] Sihavong A, Phouthavane T, Lundborg CS, Sayabounthavong K, Syhakhang L, Wahlström R. Reproductive tract infections among women attending a gynecology outpatient department in Vientiane, Lao PDR. Sex Transm Dis 2007; 34: 791-5.

[168] Bala M, Ray K, Gupta SM, Muralidhar S, Jain RK. Changing trends of antimicrobial susceptibility patterns of Neisseria gonorrhoeae in India and the emergence of ceftriaxone less susceptible N. gonorrhoeae strains. J Antimicrob Chemother 2007; 60: 582-6.

[169] Bala M, Jain RK, Ray K. Antimicrobial susceptibility profile of resistance phenotypes of Neisseria gonorrheae in India. Sex Transm Dis 2008; 35: 588-91.

[170] De Jongh M, Dangor Y, Adam A, Hoosen AA. Gonococcal resistance: evolving from penicillin, tetracycline to the quinolones in South Africa -- implications for treatment guidelines. Int J STD AIDS 2007; 18: 697-9.

[171] Moodley P, Martin IM, Pillay K, Ison CA, Sturm AW. Molecular epidemiology of recently emergent ciprofloxacin-resistant Neisseria gonorrhoeae in South Africa. Sex Transm Dis 2006; 33 : 357-60.

[172] Cao V, Ratsima E, Van Tri D, et al. Antimicrobial susceptibility of Neisseria gonorrhoeae strains isolated in 2004-2006 in Bangui, Central African Republic; Yaoundé, Cameroon; Antananarivo, Madagascar; and Ho Chi Minh Ville and Nha Trang, Vietnam. Sex Transm Dis 2008; 35: 941-5.

[173] Apalata T, Zimba TF, Sturm WA, Moodley P. Antimicrobial susceptibility profile of Neisseria gonorrhoeae isolated from patients attending a STD facility in Maputo, Mozambique. Sex Transm Dis 2009; 36: 341-3.

[174] Tapsall JW, Ndowa F, Lewis DA, Unemo M. Meeting the public health challenge of multidrug- and extensively drug-resistant Neisseria gonorrhoeae. Expert Rev Anti Infect Ther 2009; 7: 82134.

[175] Jahan Y, Begum K, Murshed M, Kabir A, Begum K. Multiple drug resistant Neisseria gonorrhoeae among females of high risk behaviour in Dhaka city. J Prev Soc Med 1999; 18: 46-51.

[176] Tapsall JW. Implications of current recommendations for thirdgeneration cephalosporin use in the WHO Western Pacific Region following the emergence of multiresistant gonococci. Sex Transm Infect 2009; $85: 256-8$.

[177] CDC. Update to CDC's Sexually Transmitted Diseases Treatment Guidelines, 2006: Fluoroquinolones No Longer Recommended for Treatment of Gonococcal Infections. MMWR 2007; 56: 332-6.

[178] Tapsall JW. Implications of current recommendations for thirdgeneration cephalosporin use in the WHO Western Pacific Region following the emergence of multiresistant gonococci. Sex Transm Infect 2009; 85: 256-8.

[179] Yokoi S, Deguchi T, Ozawa T, et al. Threat to cefixime treatment for gonorrhea. Emerg Infect Dis 2007; 13: 1275-7.

[180] WHO Western Pacific Gonococccal Antimicrobial Surveillance Programme. Surveillance of antibiotic resistance in Neisseria gonorrhoeae in the WHO Western Pacific Region, 2006. Commun Dis Intell 2008; 32: 48-51.
[181] Tapsall JW. Neisseria gonorrhoeae and emerging resistance to extended spectrum cephalosporins. Curr Opin Infect Dis 2009; 22: 87-91.

[182] Sosa J, Ramirez-Arcos S, Ruben M, et al. High percentages of resistance to tetracycline and penicillin and reduced susceptibility to azithromycin characterize the majority of strain types of Neisseria gonorrhoeae isolates in Cuba, 1995-1998. Sex Transm Dis 2003; 30: 443-8.

[183] Boslego JW, Tramont EC, Takafuji ET, et al. Effect of spectinomycin use on the prevalence of spectinomycin-resistant and of penicillinase-producing Neisseria gonorrhoeae. N Engl J Med 1987; 317: 272-8.

[184] WHO. WHO Report 2009. Global Tuberculosis Control. Epidemiology, Strategy, Financing. Geneva 2009.

[185] Doomsday DC. Postponed-Preventing and reversing epidemics of drug resistant tuberculosis. Nat Rev Microbiol 2009; 7: 81-7.

[186] Jassal M, Bishai WR. Extensively drug-resistant tuberculosis. Lancet Infect Dis 2009; 9: 19-30.

[187] CDC. Notice to Readers: Revised Definition of Extensively DrugResistant Tuberculosis. MMWR Morb Mortal Wkly Rep 2006; 55: 1176.

[188] Wright A, Zignol M, Van Deun A, et al. Global Project on AntiTuberculosis Drug Resistance Surveillance. Epidemiology of antituberculosis drug resistance 2002-07: an updated analysis of the Global Project on Anti-Tuberculosis Drug Resistance Surveillance. Lancet 2009; 373: 1861-73.

[189] Shah NS, Wright A, Bai GH, et al. Worldwide emergence of extensively drug-resistant tuberculosis. Emerg Infect Dis 2007; 13: 380-7.

[190] Borgdorff MW, Small PM. Scratching the surface of ignorance on MDR tuberculosis. Lancet 2009; 373: 1822-4.

[191] Jain A, Mondal R. Extensively drug-resistant tuberculosis: current challenges and threats. FEMS Immunol Med Microbiol 2008; 53: 145-50.

[192] WHO 2000. Guidelines for Establishing DOTS-Plus Pilot Projects for the Management of Multidrug-Resistant Tuberculosis (MDRTB). Geneva, Switzerland 2000; WHO/CDS/TB/2000.278.

[193] Mlambo CK, Warren RM, Poswa X, Victor TC, Duse AG, Marais E. Genotypic diversity of extensively drug-resistant tuberculosis (XDR-TB) in South Africa. Int J Tuberc Lung Dis 2008; 12: 99104.

[194] Stroud LA, Tokars JI, Grieco MH, et al. Evaluation of infection control measures in preventing the nosocomial transmission of multidrug-resistant Mycobacterium tuberculosis in a New York City hospital. Infect Control Hosp Epidemiol 1995; 16: 141-7.

[195] Basu S, Andrews JR, Poolman EM, et al. South African district hospitals: an epidemiological modelling study. Lancet 2007; 370: 1500-7.

[196] Planta MB. The role of poverty in antimicrobial resistance. J Am Board Fam Med 2007; 20: 533-9.

[197] Land T. Combating counterfeit drugs. Nature 1992; 355: 192.

[198] McGregor A. Counterfeit drugs flood developing world. Lancet 1997; 350: 1690 .

[199] Pecoul B, Chirac P, Trouiller P, Pinel J. Access to essential drugs in poor countries: a lost battle? J Am Med Assoc 1999; 281: 361-7.

[200] Okeke I, Lamikanra A. Quality and bioavailability of tetracycline capsules in a Nigerian semi-urban community. Int J Antimicrob Agents 1995; 5: 245-50.

[201] Agom JK, Akannii AO, Dawodu TO. Quality of ampicillin/cloxacillin preparations on the Nigerian market. Niger $\mathrm{J}$ Pharmacol 1990; 21: 36-8.

[202] Gustafsson LL, Wide K. Marketing of obsolete antibiotics in Central America. Lancet 1981; 1:31-3.

[203] Ali HM, Homeida MM, Abdeen MA. Drug dumping in donations to Sudan. Lancet 1988; 333: 538-9.

[204] Kigotho AW. Kenya's government tackles influx of sub-standard drugs. Lancet 1997; 350: 1690.

[205] Okeke IN, Lamikanra A, Edelman R. Socioeconomic and behavioral factors leading to acquired bacterial resistance to antibiotics in developing countries. Emerg Infect Dis 1999; 5: 1827.

[206] Hogerzel HV, Battersby A, Srdanovic V, Stjernstrom NE. Stability of essential drugs during shipment to the tropics. Br Med J 1992; 304: 210-2. 
[207] Shakoor O, Taylor RB, Behrens RH. Assessment of the incidence of substandard drugs in developing countries. Trop Med Int Health 1997; 2: 839-45.

[208] Ballereau F, Prazuck T, Schrive I, et al. Stability of essential drugs in the field: results of a study conducted over a two-year period in Burkina-Faso. Am J Trop Med Hyg 1997; 57: 31-6.

[209] Lansang MA, Lucas-Aquino R, Tupasi TE, et al. Purchase of antibiotics without prescription in Manila, Philippines. Inappropriate choices and doses. J Clin Epidemiol 1990; 43: 61-7.

[210] Guyon AB, Barman A, Ahmed JU, et al. A baseline survey on use of drugs at the primary health care level in Bangladesh. Bull World Health Organ 1994; 72: 265-71.

[211] Bojalil R, Calva JJ. Antibiotic misuse in diarrhea. A household survey in a Mexican community. J Clin Epidemiol 1994; 47: 14756.

[212] Hui L, Li XS, Zeng XJ, et al. Patterns and determinants of use of antibiotics for acute respiratory tract infection in children in China. Pediatr Infect Dis J 1997; 16: 560-4.

[213] Reyes H, Guiscafre H, Muñoz O, et al. Antibiotic noncompliance and waste in upper respiratory infections and acute diarrhea. J Clin Epidemiol 1997; 50: 1297-304.
[214] Meers PD. Infection control in developing countries. J Hosp Infect 1988; 11(Suppl A): 406-10.

[215] Rasniraul L, Suthienkul O, Echevarria PD, et al. Foods as a source of enteropathogens causing childhood diarrhea in Thailand. Am J Trop Med Hyg 1988; 39: 97102.

[216] Rahim Z, Aziz KM. Enterotoxigenic, hemolytic activity and antibiotic resistance of Aeromonas spp isolated from freshwater prawn marketed in Dhaka, Bangladesh. Microbiol Immunol 1994; 38: 773-8.

[217] Barza M, Gorbach SL. The need to improve antimicrobial use in agriculture: ecological and human health consequences. Clin Infect Dis 2002; 34(Suppl 3): S71-144.

[218] Radyowijati A, Haak H. Improving antibiotic use in low-income countries: an overview of evidence on determinants. Soc Sci Med 2003; 57: 733-44.

[219] Byarugaba DK. A view on antimicrobial resistance in developing countries and responsible risk factors. Int J Antimicrob Agents 2004; 24: 105-10.

[220] Tunger O, Karakaya Y, Cetin CB, Dinc G, Borand H. Rational antibiotic use. J Infect Dev Ctries 2009; 3: 88-93.

(C) Vila and Pal; Licensee Bentham Open.

This is an open access article licensed under the terms of the Creative Commons Attribution Non-Commercial License (http://creativecommons.org/licenses/ by-nc/3.0/) which permits unrestricted, non-commercial use, distribution and reproduction in any medium, provided the work is properly cited. 